\title{
An Ultrastructural Study of the Thalamic Input to Layer 4 of Primary Motor and Primary Somatosensory Cortex in the Mouse
}

\author{
Rita Bopp, Simone Holler-Rickauer, ${ }^{-K e v a n ~ A . C . ~ M a r t i n, ~ a n d ~} \mathbb{C}^{-}$Gregor F.P. Schuhknecht \\ Institute of Neuroinformatics, University of Zürich and ETH Zürich, 8057 Zürich, Switzerland
}

The traditional classification of primary motor cortex (M1) as an agranular area has been challenged recently when a functional layer 4 (L4) was reported in M1. L4 is the principal target for thalamic input in sensory areas, which raises the question of how thalamocortical synapses formed in M1 in the mouse compare with those in neighboring sensory cortex (S1). We identified thalamic boutons by their immunoreactivity for the vesicular glutamate transporter 2 (VGluT2) and performed unbiased disector counts from electron micrographs. We discovered that the thalamus contributed proportionately only half as many synapses to the local circuitry of L4 in M1 compared with S1. Furthermore, thalamic boutons in M1 targeted spiny dendrites exclusively, whereas $\sim 9 \%$ of synapses were formed with dendrites of smooth neurons in S1. VGluT2 ${ }^{+}$boutons in M1 were smaller and formed fewer synapses per bouton on average ( $1.3 \mathrm{vs}$ 2.1) than those in S1, but VGluT2 ${ }^{+}$synapses in M1 were larger than in S1 (median postsynaptic density areas of $0.064 \mu \mathrm{m}^{2}$ vs $0.042 \mu \mathrm{m}^{2}$ ). In M1 and S1, thalamic synapses formed only a small fraction ( $12.1 \%$ and $17.2 \%$, respectively) of all of the asymmetric synapses in L4. The functional role of the thalamic input to L4 in M1 has largely been neglected, but our data suggest that, as in S1, the thalamic input is amplified by the recurrent excitatory connections of the L4 circuits. The lack of direct thalamic input to inhibitory neurons in M1 may indicate temporal differences in the inhibitory gating in L4 of M1 versus S1.

Key words: barrel cortex; electron microscopy; layer 4; motor cortex; thalamocortical; VGluT2

Significance Statement

Classical interpretations of the function of primary motor cortex (M1) emphasize its lack of the granular layer 4 (L4) typical of sensory cortices. However, we show here that, like sensory cortex (S1), mouse M1 also has the canonical circuit motif of a core thalamic input to the middle cortical layer and that thalamocortical synapses form a small fraction (M1: 12\%; S1: 17\%) of all asymmetric synapses in $\mathrm{L} 4$ of both areas. Amplification of thalamic input by recurrent local circuits is thus likely to be a significant mechanism in both areas. Unlike M1, where thalamocortical boutons typically form a single synapse, thalamocortical boutons in S1 usually formed multiple synapses, which means they can be identified with high probability in the electron microscope without specific labeling.

\section{Introduction}

The eponymous feature of agranular cortical areas, which include the primary motor cortex (M1), is their lack of the cytologically distinct layer 4 (L4) that is so prominent in granular cortical areas

\footnotetext{
Received Aug. 11, 2016; revised Jan. 17, 2017; accepted Jan. 19, 2017.

Author contributions: K.A.C.M. and G.F.P.S. designed research; G.F.P.S. performed research; R.B., S.H.-R., and G.F.P.S. analyzed data; K.A.C.M. and G.F.P.S. wrote the paper.

This work was supported by the Schweizer Nationalfonds Sinergia (K.A.C.M.). We thank John C. Anderson and German Köstinger for their support. Fluorescence imaging was performed with equipment maintained by the Center for Microscopy and Image Analysis, University of Zurich. As members of the Institute of Neuroinformatics, the authors are signatories of the Basel Declaration.

The authors declare no competing financial interests.

Correspondence should be addressed to Gregor F.P. Schuhknecht, Institute of Neuroinformatics, University of Zürich and ETH Zürich, Winterthurerstrasse 190, 8057 Zürich, Switzerland. E-mail: sgregor@ethz.ch.

DOI:10.1523/JNEUROSCI.2557-16.2017

Copyright $\odot 2017$ the authors $\quad 0270-6474 / 17 / 372435-14 \$ 15.00 / 0$
}

(Brodmann, 1909). In sensory areas, the granular L4 is a primary site of thalamic input and thus is considered to be the first stage of processing in the laminar hierarchy (Hubel and Wiesel, 1962). Not surprisingly, in the absence of a granular L4, theories about the cortical computation in M1 have proposed a quite different mode of interlaminar processing (Shipp, 2005; Shepherd, 2009; Shipp et al., 2013) that completely exclude the thalamocortical input.

From time to time, reports have emerged of a L4 in M1, a layer composed of a thin band of pyramidal cells (Krieg, 1946; Skoglund et al., 1997; García-Cabezas and Barbas, 2014); and, as in granular cortex, thalamic afferents do innervate the middle layers of M1 (Strick and Sterling, 1974; Shinoda and Kakei, 1989; Yamamoto et al., 1990; Nakano et al., 1992; Kuramoto et al., 2009). Recordings from slices of mouse M1 by Yamawaki et al. 
(2015) revealed a layer of pyramidal neurons located at the L3/5A border that could be monosynaptically activated from the thalamus and that projected to the upper layers, as do the L4 spiny neurons of sensory cortices. Barbas and García-Cabezas (2015) then speculated that L4 of M1 performs the same basic functions as in sensory cortices. Although this hypothesis is intriguing, many details about the thalamocortical projection to the middle layers of M1 are lacking, and thus its degree of similarity to L4 of sensory cortex remains unclear.

One key aspect of the thalamic input to sensory cortices is the small number of synapses it actually provides, despite its critical role in driving the cortex. In our quantitative studies of primary visual cortex (V1) in cat and monkey we found that only $5-10 \%$ of the asymmetric synapses in $\mathrm{L} 4$ are thalamic in origin (Ahmed et al., 1994; Latawiec et al., 2000; da Costa and Martin, 2009), which means that thalamic afferents form only a few hundred synapses with each neuron. In cat and monkey between $90 \%$ and $95 \%$ of the thalamic synapses were formed with pyramidal or spiny stellate cells, the remainder with smooth (putative GABAergic inhibitory) neurons (Ahmed et al., 1994; Latawiec et al., 2000; da Costa and Martin, 2009). To drive cortex with so few synapses, it was supposed that they must be strong. Physiological studies in cat V1 in vitro showed that, indeed, the thalamic synapses did have a larger amplitude EPSP with a very low coefficient of variance, but also that they depressed strongly with repeated activation (Stratford et al., 1996). Similar dynamics were reported for thalamocortical synapses in rodent somatosensory cortex (Gil et al., 1999; Bruno and Sakmann, 2006). In vivo, the spontaneous activity of the thalamus will depress the amplitude of the EPSPs, thus making the number of thalamic synapses simultaneously active a critical factor in driving the postsynaptic cell (Bruno and Sakmann, 2006; Banitt et al., 2007).

Comparable numbers of thalamocortical synapses, their size distribution, and their targets are unknown in M1 for any species. The present study was designed to answer this question by making a quantitative assessment of the thalamocortical projection to the forepaw area of $\mathrm{M} 1$ and comparing it with the barrel region of primary somatosensory cortex (S1). We exploited the fact that one of the vesicular glutamate transporters (VGluT2) is a selective marker for thalamocortical boutons (Nahmani and Erisir, 2005; Coleman et al., 2010). Our examination of synapses formed by VGluT2-positive $\left(\mathrm{VGluT2}^{+}\right.$) boutons in $\mathrm{M} 1$ and $\mathrm{S} 1$ indicates that the motor cortex possesses a canonical laminar pattern of thalamic innervation and that, in both M1 and S1, the thalamocortical synapses form a small fraction of the excitatory input to a L4 neuron.

\section{Materials and Methods}

Animals. Three adult male B6/C57 mice (Harlan Laboratories) under the license of K.A.C.M. (approved by Cantonal Veterinary Office, Zurich) were used in this study. The animals were anesthetized with pentobarbital and perfused transcardially with saline, followed by a solution of paraformaldehyde (4\%), picric acid (15\%), and glutaraldehyde $(0.3 \%)$. The measured brain shrinkage with this solution was $11 \%$.

Immunohistochemistry. All analyses of M1 were performed in the forelimb representation region (Tennant et al., 2011) and all analyses of S1 were performed within barrels. Areas were identified by conventional criteria (Paxinos and Franklin, 2004). The brain was removed from the skull and sectioned coronally at $80 \mu \mathrm{m}$. Sections were incubated in an ascending sucrose ladder for cryoprotection and then rapidly frozen individually in liquid nitrogen, followed by treatment in $0.5 \%$ sodium borohydrate, $3 \%$ hydrogen peroxide, and $10 \%$ methanol. After blocking in 1\% BSA and 5\% NGS in PBS for 30 min at room temperature (RT), we incubated the sections in primary antibody (anti-VGluT2, made in guinea pig; Millipore catalog \#AB2251, RRID:AB_1587626, 1:10.000) in $1 \%$ BSA and $1 \%$ NGS in PBS overnight at $4^{\circ} \mathrm{C}$. After this, sections were washed and incubated with a biotinylated secondary antibody (Vector Laboratories catalog \#BA-7000, RRID:AB_2336132, 1:200) at RT for $3 \mathrm{~h}$. After washing, we kept the sections in Vectastain $\mathrm{ABC}$ Kit (Vector Laboratories catalog \#PK-6100, RRID:AB_2336819) overnight at $4^{\circ} \mathrm{C}$ and visualized the biotin using a protocol containing nickel-diaminobenzidine tetrahydrochloride and hydrogen peroxide treatment. Those sections that were selected for electron microscopy (EM) were then treated with $1 \%$ osmium tetroxide for $20 \mathrm{~min}$, dehydrated using an ascending series of ethanol and propylene oxide (including treatment in $1 \%$ uranyl-acetate in $70 \%$ ethanol), and flat-mounted in Durcupan resin (Sigma-Aldrich). We have measured the shrinkage through all stages of processing in both cat (da Costa and Martin, 2009) and mouse (unpublished observations) cortex. The aldehyde fixation-perfusion produced a consistent $11 \%$ shrinkage. After washing out the sucrose used for cryoprotection, immunostaining the floating $80-\mu \mathrm{m}$-thick sections, osmicating, and then embedding the sections for light microscopy and EM, we measured no additional shrinkage of the tissue beyond that of the initial fixation-perfusion shrinkage of $11 \%$. We have not corrected for this $11 \%$ shrinkage in any of the quantitative measurements or calculations reported in the Results.

To identify all the layers of termination of the thalamic afferents in M1 and S1, we additionally performed a VGluT2 and neuronal nuclei (NeuN) double labeling in one mouse, visualized with fluorescing secondary antibodies. NeuN was particularly helpful in identifying the cortical laminae in fluorescent images. In this protocol, we added $1 \%$ Triton X-100 and $10 \%$ donkey serum to the blocking solution and $0.4 \%$ Triton X-100 and 2\% donkey serum to the primary antibody solution (VGluT2 as above and anti-NeuN, made in mouse, Millipore catalog \#MAB377, RRID:AB_2298772, 1:500) and incubated the sections for $48 \mathrm{~h}$ at $4^{\circ} \mathrm{C}$. Treatment in the secondary antibody solution (1\% BSA, $2 \%$ donkey serum, $1 \%$ NGS, $0.4 \%$ Triton X-100 with Alexa Fluor 488, donkey-antimouse (Thermo Fisher Scientific catalog \#A-21202, RRID:AB_2535788) and Alexa Fluor 555, goat-anti-guinea pig (Thermo Fisher Scientific catalog \#A-21435, RRID:AB_2535856), both 1:500) was done at $4^{\circ} \mathrm{C}$ for $12 \mathrm{~h}$. Sections were mounted in Vectashield mounting medium containing DAPI (Vector Laboratories catalog \#H-1000, RRID:AB_2336789) and imaged using a Leica SP8 confocal laser-scanning microscope (10X dry objective, numerical aperture 0.3 ); subsequent image processing was done in ImageJ and Photoshop.

$E M$. Sections that contained L4 in barrel and motor cortex were cut into $50 \mathrm{~nm}$ ultrathin sections and collected on Pioloform-coated singleslot copper grids and treated with lead-citrate (after embedding). Unbiased disector counts of VGluT2-labeled and -unlabeled asymmetric synapses was performed as described by da Costa et al. (2009). Briefly, we randomly chose one section within the superficial $3 \mu \mathrm{m}$ of the tissue block where penetration of antibody was satisfactory and randomly placed a grid of equally spaced sampling locations onto this section. Photographs of the sampling sites were taken at $13,500 \times$ and we counted the synapses that disappeared within a $5 \times 5 \mu \mathrm{m}$ square from reference to lookup section (separated by one intervening section, giving a disector volume of $2.5 \mu \mathrm{m}^{3}$ ). Reference and lookup section were then reversed and we counted in the opposite direction.

All synapses were examined in serial sections and were classified as either asymmetric (Gray's type 1) or symmetric (Gray's type 2) (Gray, 1959; Colonnier, 1968). Postsynaptic structures were also examined in multiple sections and identified as dendritic spines, dendritic shafts, or somata according to their morphological features (Gray, 1959; Colonnier, 1968; Peters et al., 1991; Peters and Palay, 1996).

$3 D$ bouton reconstructions. As with the unbiased disector method, we chose random locations on a starting section for the reconstruction of boutons forming labeled and unlabeled asymmetric synapses $\left(\right.$ VGluT2 $\left.^{-}\right)$. Serial electron micrographs $(13,500 \times)$ were generated for all VGluT2 ${ }^{+}$and VGluT2 ${ }^{-}$boutons contained in the initial section and fully reconstructed and digitized using the TrakEM2 plugin of ImageJ. VGluT2 ${ }^{-}$boutons appeared more frequently and, to sample similar numbers of VGluT2 ${ }^{+}$and VGluT2 ${ }^{-}$boutons, in some sets of serial micrographs, we reconstructed only the VGluT2 ${ }^{+}$boutons. We chose the 

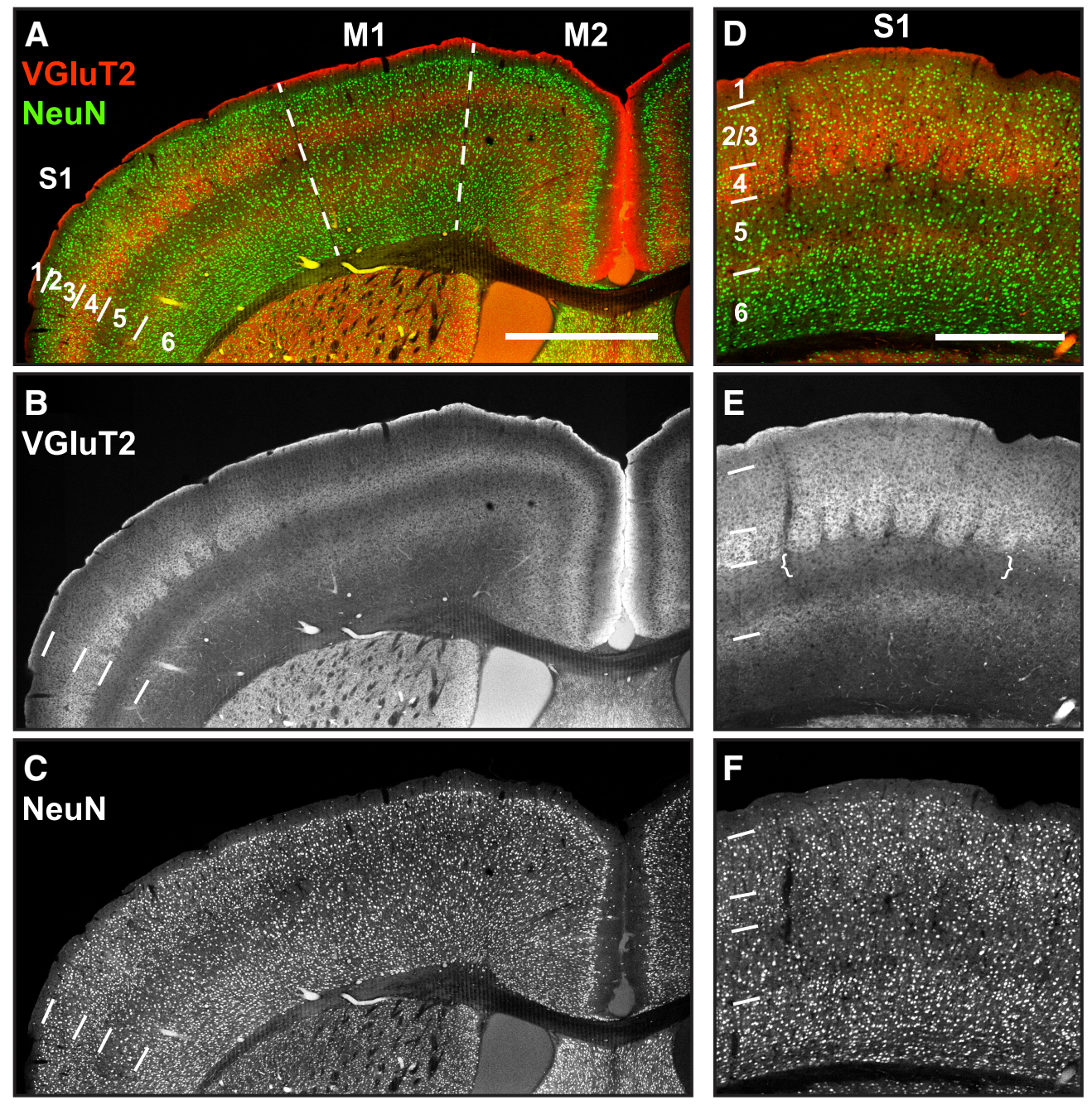

Figure 1. Thalamorecipient layers in sensory and motor areas revealed by dual labeling of VGluT2 and NeuN. $\boldsymbol{A}-\boldsymbol{C}$, Coronal section ( $0.48 \mathrm{~mm}$ anterior of the bregma) containing M2, M1, and S1. Scale bar, $1 \mathrm{~mm}$. A, Merge of micrographs of VGluT2- and NeuN-stained sections with cortical layers $1-6$ indicated. $\boldsymbol{B}$, VGluT2 label occurs in three distinct bands. The L4 band is most salient in S1 and can be followed medially into M1 and M2, where it becomes fainter and thinner. C, NeuN staining for neuronal somata revealing cytoarchitecture, L4 in S1 is composed of small and densely packed cells; in M1, it is present but less easily identified. $\boldsymbol{D}-\boldsymbol{F}$, Coronal section containing vibrissal barrel cortex (0.48 mm posterior of bregma). Scale bar, $500 \mu \mathrm{m}$. $\boldsymbol{D}$, Merge of micrographs of VGluT2- and NeuN-stained sections with cortical layers 1-6 indicated. $\boldsymbol{E}$, VGluT2 fluorescence is strongest in L4 barrels and less intense in the septa. VGluT2 label is also present in L1, L2/3, upper L5 (brackets), and at the $L 5 / 6$ border. $F$, NeuN staining revealing the cytoarchitecture of barrel cortex.

method of reconstructing either all or none of the VGluT2 ${ }^{-}$boutons in a starting section to avoid size biases. Using a sampling grid to select a subset of VGluT2 ${ }^{-}$boutons for reconstruction would have biased our selection toward larger VGluT2 ${ }^{-}$boutons because objects with large cross-sectional areas have a higher probability of falling on a sampling spot. For both samples, only boutons that could be reconstructed entirely throughout the set of serial sections were included in the analysis. Bouton, spine head, and mitochondria volume and synapse area were then measured in the same software by multiplying the manually traced areas with the section thickness $(50 \mathrm{~nm})$. 3D reconstructions of representative structures were exported into the Blender software, fitted with a skin, and rendered to offer a 3D impression. Subsequent data analysis and visualization were performed with MATLAB R2015a (The MathWorks) and GraphPad Prism 6.

Estimation of synaptic vesicle density. We estimated the vesicle density of VGluT2 ${ }^{-}$and VGluT2 ${ }^{+}$boutons from single electron micrographs. Vesicles were counted only in sections in which the postsynaptic density (PSD) was also present and in which the lumen of the vesicles were clearly visible; that is, not obscured by reaction end-product. Vesicles were annotated in single sections only when they appeared as full profiles, meaning that at least half of the vesicle was contained in the section. Vesicles that appeared exceptionally small (with a radius of $<4 \mathrm{~nm}$ ) were excluded because they were assumed to be sliced in a way that only the cap of the vesicle was contained in the section. Because vesicles that are partially contained in the section $(\geq 50 \%)$ were also annotated as full profiles, we corrected our raw counts with the Abercrombie factor (LinderstrømLang et al., 1935; Abercrombie, 1946). Abercrombie's method is reliable for spherical particles of similar size and requires the section thickness to exceed the particle height by a factor of at least 1.5 (Clarke, 1992). We made a histogram of the distribution of the vesicle lumen radius in unlabeled boutons. The mean radius was $9 \mathrm{~nm}$ and, by adding $6 \mathrm{~nm}$ for each vesicle membrane, we estimated the mean vesicle height $\bar{H}$ (external diameter) to be $30 \mathrm{~nm}$ (Schikorski and Stevens, 1997). Because synaptic vesicles fulfill the criteria imposed by Abercrombie's method, we were able to use it in its original form, adopted from Clarke (1992), as follows:

$$
\frac{N}{n}=\frac{T}{T+\bar{H}}
$$

where $N$ is the corrected number of vesicles, $n$ the raw count, $T$ the section thickness (50 nm), and $\overline{\mathrm{H}}$ the mean height. The corrected vesicle count was divided by the respective bouton volume in which the vesicles were counted (the bouton area minus the area of the mitochondria contained in the bouton multiplied by the section thickness). 

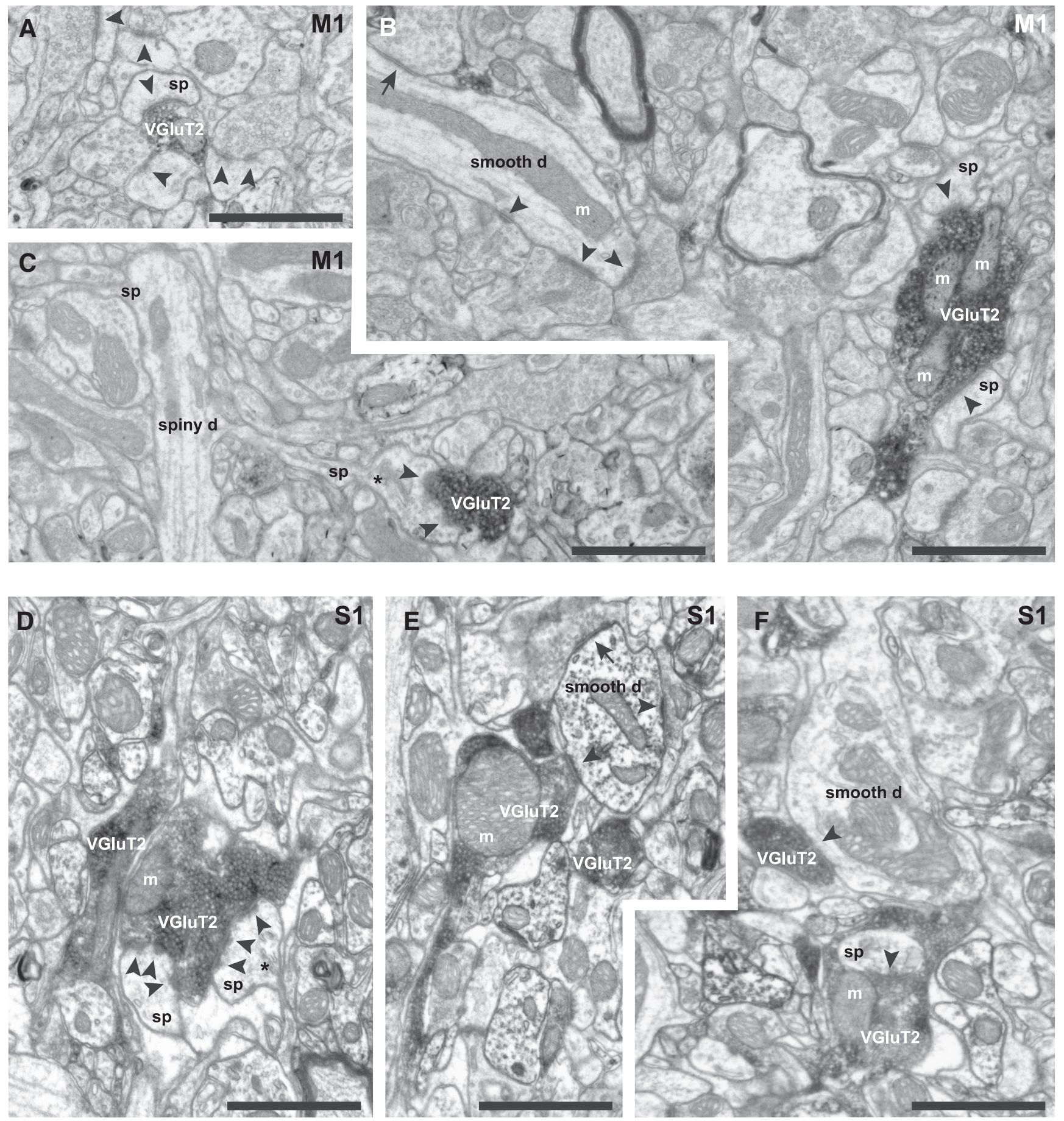

Figure 2. Electron micrographs of VGluT2-labeled boutons in $L 4$ of motor cortex $(\boldsymbol{A}-\boldsymbol{C})$ and vibrissal barrel cortex $(\boldsymbol{D}-\boldsymbol{F})$. Scale bars in all panels, $1 \mu \mathrm{m}$. $\boldsymbol{A}, \mathrm{VGluT2}{ }^{+}$bouton forming an asymmetric synapse (arrowhead) with a spine (sp) in L4 of M1. VGluT2 label appears as electron-dense material on synaptic vesicles. Unlabeled boutons in the surrounding neuropil also form asymmetric synapses with spines (arrowheads). $\boldsymbol{B}$, Single VGluT2 ${ }^{+}$boutons often appeared large in cross-section, contained mitochondria (m), and formed synapses with multiple target spines (sp; arrowheads). A smooth (putative GABAergic) dendrite (smooth d) traverses and forms three asymmetric synapses (arrowheads) and one symmetric synapse (arrow) with unlabeled boutons. C, A VGluT2 ${ }^{+}$bouton forms a perforated synapse (two arrowheads) with a spine head containing a spine apparatus (asterisk). The spine originates from a dendrite traversing through (spiny d). D, A large VGluT2 ${ }^{+}$bouton in L4 of vibrissal barrel cortex forms two perforated synapses (arrowheads) on spines (sp), one of which contains a spine apparatus (asterisk). A second elongated VGluT2-labeled bouton (left) formed no synapses in this section. $\boldsymbol{E}$, A VGluT2 $^{+}$boutons forms a synapse (arrowhead) with a smooth dendrite (smooth d). The dendrite forms another asymmetric synapse with an unlabeled bouton (arrowhead) and a symmetric synapse (arrow) with an unlabeled (putative GABAergic) bouton, which contains pleomorphic vesicles. $\boldsymbol{F}$, Some target spine heads are enveloped completely by the VGluT2 ${ }^{+}$bouton. In the same section, a VGluT2 ${ }^{+}$bouton forms an asymmetric synapse (arrowhead) with a smooth dendrite (smooth d). 
Table 1. Summary of unbiased disector counts of synapses made by VGluT2 ${ }^{+}$boutons in M1 and S1 L4 for 3 mice

\begin{tabular}{|c|c|c|c|c|c|c|}
\hline \multirow[b]{2}{*}{ Mouse } & \multicolumn{3}{|l|}{ M1 } & \multicolumn{3}{|l|}{ S1 } \\
\hline & No. of synapses & $\begin{array}{l}\text { Synapses density per } \mu \mathrm{m}^{3} \pm \text { SEM } \\
\left(N_{\mathrm{V}}^{\text {VGluT2 }} \text { and } N_{\mathrm{V}}^{\text {asym }}\right)\end{array}$ & $\begin{array}{l}\text { Percentage of } \\
\text { VGluT2 synapses }\end{array}$ & No. of synapses & $\begin{array}{l}\text { Synapse density per } \mu \mathrm{m}^{3} \pm \text { SEM } \\
\left(N_{\mathrm{V}}^{\text {VGluT2 }} \text { and } N_{\mathrm{V}}^{\text {asym }}\right)\end{array}$ & $\begin{array}{l}\text { Percentage of } \\
\text { VGluT2 synapses }\end{array}$ \\
\hline 1 & $\begin{array}{l}\text { VGluT2: } 85 \text { (218) } \\
\text { all asym: } 594 \text { (154) }\end{array}$ & $\begin{array}{l}\text { VGluT2: } 0.156 \pm 0.018 \\
\text { all asym: } 1.543 \pm 0.059\end{array}$ & $10.1 \%$ & $\begin{array}{l}\text { VGluT2: } 162(316) \\
\text { all asym: } 724(228)\end{array}$ & $\begin{array}{l}\text { VGluT2: } 0.205 \pm 0.017 \\
\text { all asym: } 1.270 \pm 0.046\end{array}$ & $16.1 \%$ \\
\hline 2 & $\begin{array}{l}\text { VGluT2: } 45 \text { (82) } \\
\text { all asym: } 278(72)\end{array}$ & $\begin{array}{l}\text { VGluT2: } 0.220 \pm 0.033 \\
\text { all asym: } 1.544 \pm 0.080\end{array}$ & $14.2 \%$ & $\begin{array}{l}\text { VGluT2: } 46(80) \\
\text { all asym: } 208(72)\end{array}$ & $\begin{array}{l}\text { VGluT2: } 0.230 \pm 0.038 \\
\text { all asym: } 1.156 \pm 0.083\end{array}$ & $19.9 \%$ \\
\hline 3 & $\begin{array}{l}\text { VGluT2: } 44(88) \\
\text { all asym: } 310(74)\end{array}$ & $\begin{array}{l}\text { VGluT2: } 0.200 \pm 0.030 \\
\text { all asym: } 1.676 \pm 0.080\end{array}$ & $11.9 \%$ & $\begin{array}{l}\text { VGluT2: } 48(80) \\
\text { all asym: } 261(68)\end{array}$ & $\begin{array}{l}\text { VGluT2: } 0.240 \pm 0.036 \\
\text { all asym: } 1.535 \pm 0.084\end{array}$ & $15.6 \%$ \\
\hline & & & $12.1 \%$ & & & $17.2 \%$ \\
\hline
\end{tabular}

We counted VGluT2 ${ }^{+}$and unlabeled asymmetric synapses ("all asym" is the sum of labeled and unlabeled synapses) in a large number of disectors (indicated in parentheses). Then, we derived the density of VGluT2 ${ }^{+}$synapses ( $N_{\mathrm{V}}^{\mathrm{VGluT2}}$ ) and all asymmetric synapses (VGluT2 ${ }^{+}$plus unlabeled, $N_{V}^{\text {asym }}$ ) by dividing the synapse count by the respective number of disectors analyzed, and by the disector volume $\left(2.5 \mu \mathrm{m}^{3}\right)$. Synapse densities are given with SEM. Finally, we calculated the percentage of VGluT2 ${ }^{+}$synapses out of all asymmetric synapses by dividing $N_{\mathrm{V}}^{\mathrm{VGluT2}}$ by $N_{\mathrm{V}}^{\text {asym }}$.

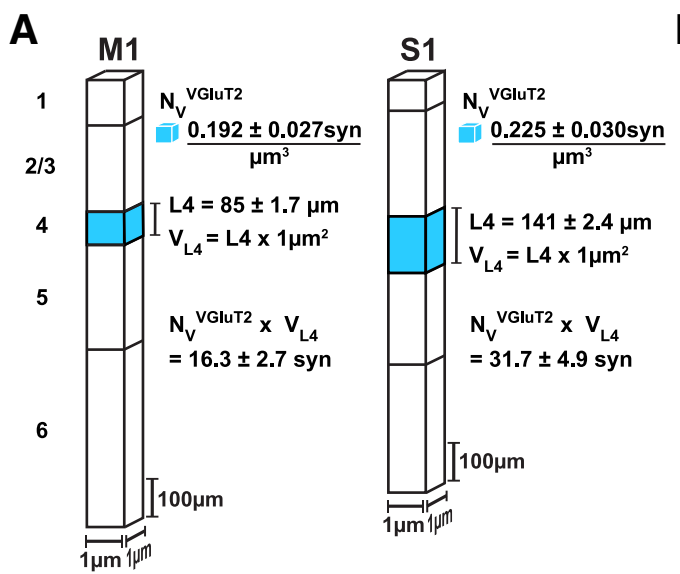

B

Figure 3. Summary of the unbiased disector counts. $\boldsymbol{A}$, Thalamocortical pathway to M1 L4 provides approximately half as many synapses compared with $\mathbf{S 1}$. The density of thalamocortical synapses in the neuropil of a layer ( $N_{\mathrm{V}}^{\mathrm{VGluT} 2} \pm \mathrm{SEM}$ ) and the absolute thickness of the target layer (L4 \pm SEM) determine how many synapses (syn) that thalamic projection contributes to the respective area. To compare the absolute number of VGluT2 synapses in M1 and S1 L4, we constructed hypothetical cuboid tissue blocks of M1 and S1 with a base area of $1 \mu \mathrm{m}^{2}$. By multiplying $N_{\mathrm{V}}^{\mathrm{VGluT2}}$ by the volume of the respective $\mathrm{L} 4\left(V_{\mathrm{L} 4}\right)$, we derived an absolute number of VGluT2 ${ }^{+}$synapses for M1 and $\mathrm{S1}$ L4. In M1, the absolute number of VGluT2 ${ }^{+}$synapses was only half that of $S 1$ (the statistical range is determined by the accumulated SEM of $N_{\mathrm{V}}^{\mathrm{VGluT2}}$ and L4 thickness). Scale bars indicate scales for cortical surface and individual layers. $\boldsymbol{B}$, Postsynaptic targets of VGluT2 ${ }^{+}$ boutons in unbiased physical disector counts for M1 and S1. The respective percentage is indicated above each bar (spine synapses: $n=173$ in M1 and 231 in S1, smooth shaft synapses: $n=1$ in M1 and 24 in S1, spiny shaft synapses: $n=0$ in M1 and 1 in S1).

\section{Results}

\section{VGluT2 immunohistochemistry reveals the thalamorecipient} middle layer in motor cortex

To obtain a qualitative comparison between the termination zones of thalamic afferents in M1 and S1, coronal sections containing these areas were immunostained with an antibody directed against VGluT2. In addition, an antibody directed against $\mathrm{NeuN}$ was used to identify the cortical lamination on the basis of its cytoarchitecture. The coronal slice shown in Figure $1, A-C$, contained anterior $\mathrm{S} 1$, the forelimb representation of $\mathrm{M} 1$, and posterior secondary motor cortex (M2). In such slices, VGluT2 labeling revealed three distinct bands of high fluorescence in parallel to the pia and white matter, which could be traced through all three areas (Fig. $1 A-C$ ). The most dorsal band was located directly beneath the pia, in upper L1. The middle band was most prominent in S1: it was coextensive with the granular L4, as identified by the NeuN staining (Fig. 1C,F). From there, it extended medially into M1 and M2, where it narrowed, moved slightly more superficial, and had decreased fluorescence intensity. The third, most ventral band was located at the L5/6 border. In M1, it appeared diffuse and had a less sharp separation toward L5 compared with S1.

In S1, VGluT2-labeling revealed the location of barrels in L4 (Fig. 1D-F), which appeared as patches of high fluorescence sep- arated by horizontal stripes of lower fluorescence, which are the interbarrel septa (Fig. 1E). There were also bands of fainter fluorescence in upper $\mathrm{L} 5$ directly below the barrels (Fig. $1 E$, brackets), in lower L2/3, and a thin band in L1 (Fig. $1 E$ ).

\section{VGluT2 ${ }^{+}$boutons in S1 and M1 reveal features attributed to thalamocortical boutons in sensory areas}

VGluT2 is expressed primarily on synaptic vesicles (Hisano et al., 2000; Fremeau et al., 2001; Varoqui et al., 2002), so in the EM, the vesicle membranes appeared intensely stained by reaction product and only the paler lumen could be used to distinguish between individual vesicles (Fig. 2). The VGluT2 ${ }^{+}$boutons were filled with synaptic vesicles. The synaptic cleft and PSD were unaffected by the staining and the mitochondria inside labeled boutons could be identified and traced easily. All VGluT2 ${ }^{+}$boutons formed asymmetric (Gray's type 1) synapses (Fig. 2, arrowheads). In single electron micrographs, cross-sections of labeled boutons in M1 and S1 showed a similar morphology: they were often relatively large compared with unlabeled boutons in the surrounding neuropil, with diameters of up to $2 \mu \mathrm{m}$ (Fig. $2 B, D$ $F)$. In some cases, they formed synapses with two or three different targets in the same section (Fig. $2 B, D$ ) and often formed perforated synapses (Fig. 2C,D). The predominant targets were dendritic spines (Fig. 2, "sp"), which sometimes contained a 

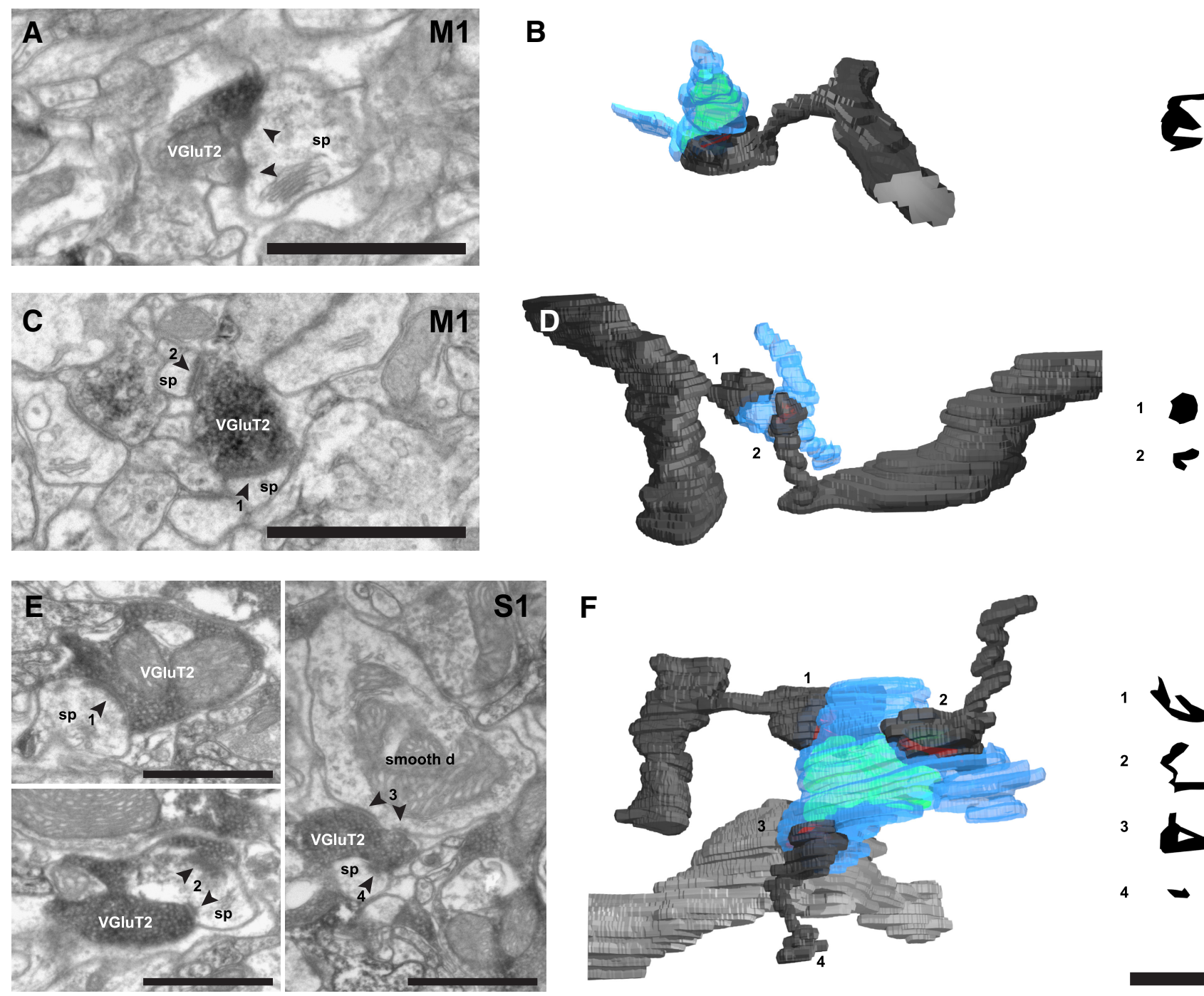

1

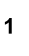

2

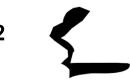

3

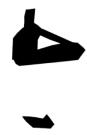

Figure 4. Representative 3D reconstructions of VGluT2 ${ }^{+}$boutons and their postsynaptic densities and targets in $\mathrm{L} 4$ of $\mathrm{M} 1$ and $\mathrm{S1}$. $A-D, \mathrm{VGluT2}{ }^{+}$boutons in $\mathrm{M} 1 \mathrm{~L} 4 . E, F, \mathrm{VGluT2}{ }^{+}$bouton in $\mathrm{S} 1$ L4. $\boldsymbol{A}$, Electron micrograph of a VGluT2 ${ }^{+}$bouton forming a single perforated synapse (arrowheads) on a dendritic spine (sp). $\boldsymbol{B}$ Left, Reconstruction of the VGluT2 ${ }^{+}$bouton from $\boldsymbol{A}$ (blue), mitochondrion inside the bouton (green), PSD (red), and dendritic spine with a segment of its parent dendrite (black). Right, en face representation of the PSD. C, Electron micrograph of a VGluT2 ${ }^{+}$ bouton in $\mathrm{L} 4$ of M1, forming two synapses, which are numbered. D Left, Reconstruction of the VGluT2 ${ }^{+}$bouton and its targets shown in $C$. Spines are indicated with numbers corresponding to the synapses that they receive, as seen in C. Right, en face representations of the two PSDs. E, Electron micrographs of a VGluT2 ${ }^{+}$bouton in L4 of S1, forming four synapses (numbered). Synapse 3 was formed with the shaft of a smooth dendrite. $\boldsymbol{F}$ Left, Reconstruction of the $V G l u T 2^{+}$bouton and its postsynaptic targets shown in $\boldsymbol{E}$ (smooth dendrite in gray). Right, En face representations of the four PSDs made by this bouton. Scale bars, $1 \mu \mathrm{m}$.

A

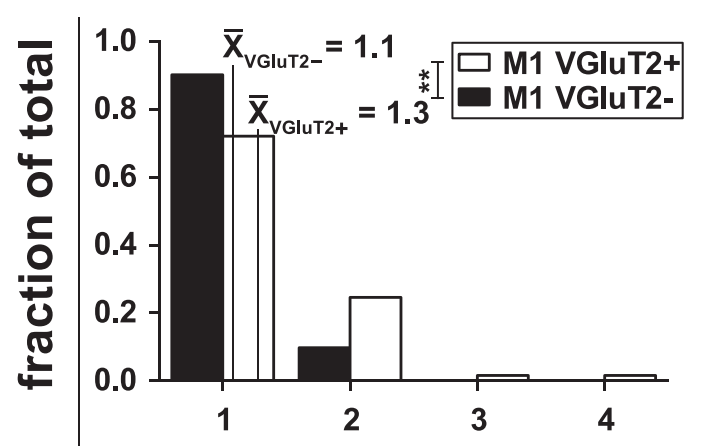

B

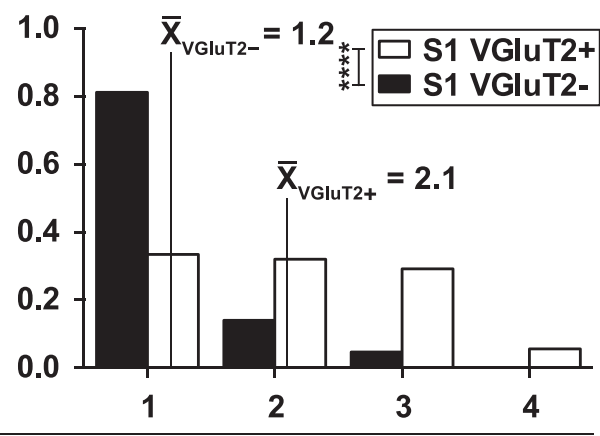

number of synapses per bouton

Figure 5. Comparison of the number of synapses made by VGluT2 ${ }^{+}$boutons in $\mathrm{M} 1$ and S1 L4. A, VGluT2 ${ }^{+}$boutons in M1 L4 $(n=61)$ predominantly form a single synapse, as did unlabeled boutons forming asymmetric synapses (VGluT2 $\left.{ }^{-}, n=82\right)$. $\boldsymbol{B}$, VGluT2 $^{+}$boutons in $\mathrm{S1} \mathrm{L} 4(n=72)$ predominantly form multiple synapses (VGluT2 $\left.{ }^{-}, n=64\right) . \bar{X}$ gives the arithmetic mean. The nonparametric $M-W$ test was used for statistical analysis. ${ }^{* *} p \leq 0.01 ;{ }^{* * * *} p \leq 0.0001$. 

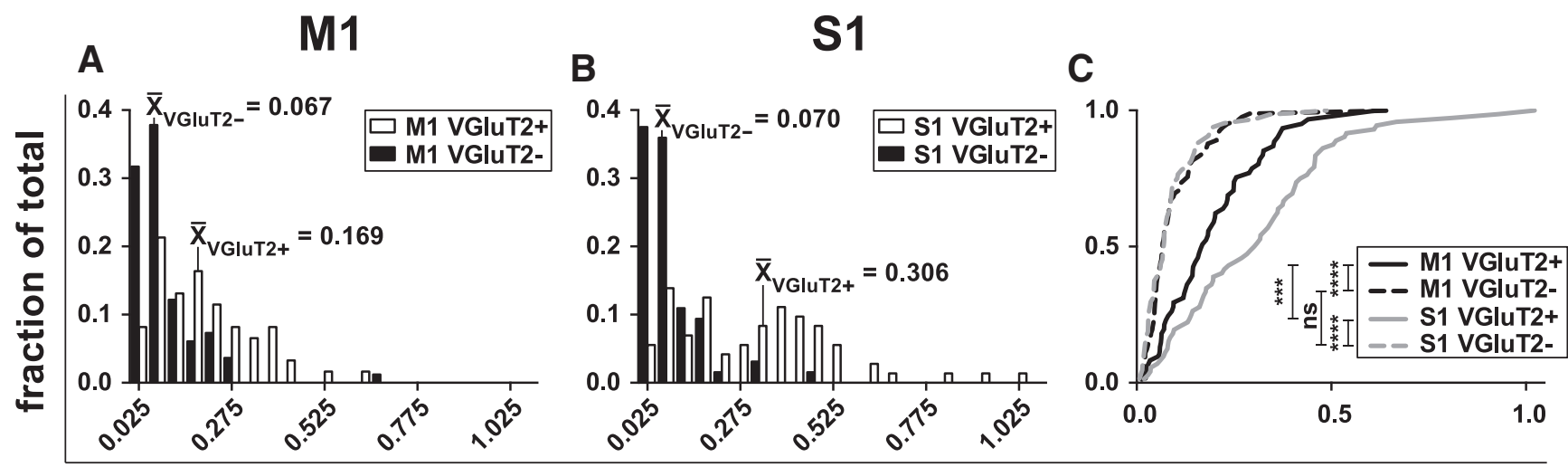

\section{bouton volume $\left[\mu \mathrm{m}^{3}\right]$}
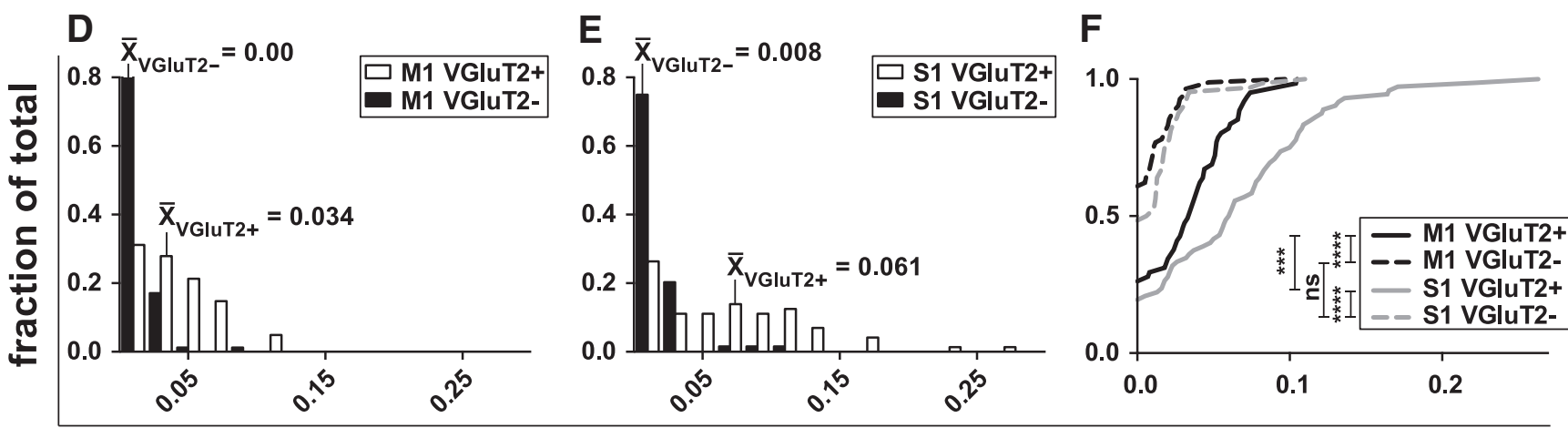

\section{mitochondria volume $\left[\mu^{3}\right]$}

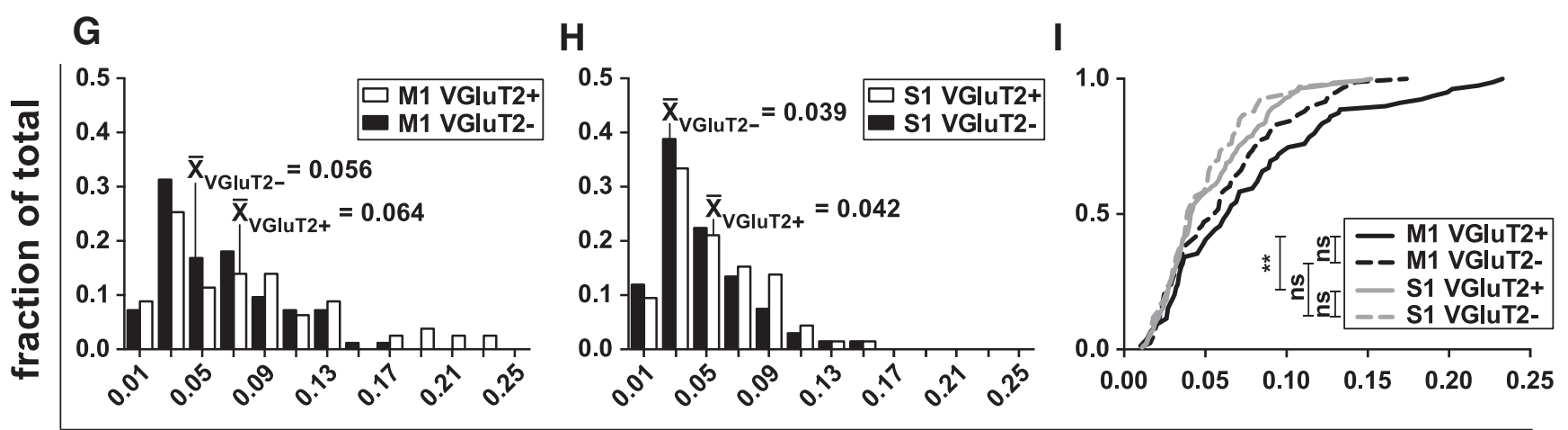

\section{postsynaptic density area $\left[\mu \mathrm{m}^{2}\right]$}
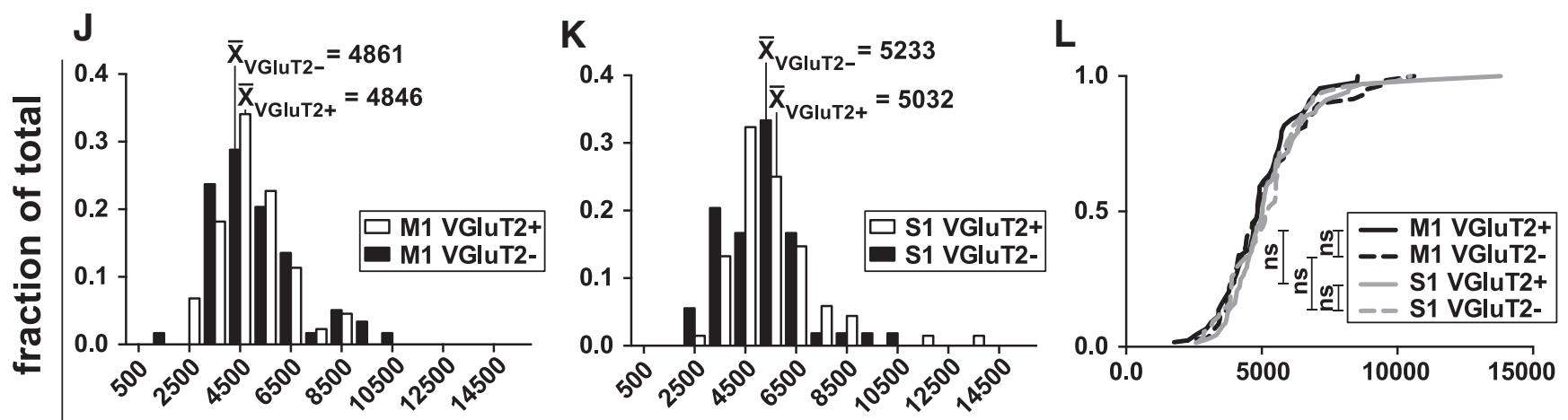

\section{estimated vesicle density $\left[\mu^{-3}\right]$}

Figure 6. Morphological features of reconstructed VGluT2 ${ }^{+}$and VGluT2 ${ }^{-}$boutons in M1 and S1 L4. A-C, Distributions of the total volume of boutons in M1 $\left(A ; \mathrm{VGluT2}{ }^{+}, n=61 ; \mathrm{VGluT2}{ }^{-}\right.$, $n=82)$ and in $\mathrm{S1}\left(\boldsymbol{B} ; \mathrm{VGluT2}^{+}, n=72 ; \mathrm{VGluT2}^{-}, n=64\right) ; \overline{\boldsymbol{X}}$ is the median. C, Cumulative histogram of the data in $\boldsymbol{A}$ and $\boldsymbol{B}$. $\boldsymbol{D}-\boldsymbol{F}$, Distributions of the (Figure legend continues.) 
prominent spine apparatus (Fig. 2C,D, asterisks). In S1, we observed that VGluT2 ${ }^{+}$boutons occasionally formed synapses with a smooth dendrite (Fig. 2E, F, "smooth d") and, more rarely, the soma of a cell. From this first qualitative assessment, it was evident that VGluT2 ${ }^{+}$boutons in both areas exhibited features that are commonly attributed to thalamocortical boutons in L4 of sensory areas. These features include a large size, the formation of asymmetric synapses, many of which had perforated PSDs, and multisynaptic boutons (Winfield and Powell, 1983; Freund et al., 1985b; Keller et al., 1985; Freund et al., 1989; Peters et al., 1991).

\section{Thalamocortical pathway to M1 L4 provides approximately half as many synapses per unit surface area as S1 L4}

Nothing is known about the anatomical "weight" of the thalamocortical projection to L4 of motor cortex. VGluT2 fluorescence appeared less intense in L4 of M1 compared with S1 (Fig. 1), suggesting a lower number of thalamocortical boutons. We used EM to determine the proportion of synapses being made by VGluT2 $^{+}$boutons in L4 of M1 and compared it with L4 in S1. This analysis in M1 and S1 allowed us to validate the VGluT2 method against previous quantitative estimates of the thalamic afferents to $S 1$ and to compare the numbers against a well studied sensory thalamocortical projection.

We counted the asymmetric synapses made by VGluT2labeled boutons and the asymmetric synapses made by unlabeled boutons (VGluT2 ${ }^{-}$) using an unbiased physical disector method for rare events (da Costa et al., 2009). We randomly assigned sampling sites on ultrathin reference sections and took photographs of the sampling sites only when they contained a labeled profile. Synapses were counted when they disappeared from the reference to a lookup section, which were separated by one intervening section. From this, we calculated the mean density of all asymmetric synapses (labeled and unlabeled) in the neuropil within the volume of the disectors that were photographed $\left(N_{\mathrm{V}}^{\mathrm{asym}}\right)$. The mean density of labeled synapses $\left(N_{\mathrm{V}}^{\mathrm{VGluT2}}\right)$ was calculated from the number of labeled synapses over the volume of all sampling sites, both those photographed and those not photographed.

Our data are summarized in Table 1. Synapses made by VGluT2 $^{+}$boutons constituted $17.2 \%$ of the total number of asymmetric synapses in the neuropil of L4 in S1 and 12.1\% of L4 in M1 (388 sites sampled in M1 and 476 sites sampled in S1 over 3 mice). This difference was due to the higher density of synapses formed by VGluT2 ${ }^{+}$boutons $\left(N_{\mathrm{V}}^{\mathrm{VGluT2}}\right)$ in L4 of $\mathrm{S} 1\left(0.225 \mu \mathrm{m}^{-3}\right)$ than in $\mathrm{M} 1\left(0.192 \mu \mathrm{m}^{-3}\right)$.

The absolute anatomical "weight" of the thalamocortical projection must include not just the density of VGluT2 ${ }^{+}$synapses in L4, but also the volume of the thalamocortical termination zone. We thus estimated the absolute number of thalamocortical synapses in L4 of M1 and S1 that would be present in a hypothetical

\footnotetext{
(Figure legend continued.) mitochondria volume inside reconstructed boutons in M1 (D; VGluT2 $^{+}, n=61$; VGluT2 $\left.{ }^{-}, n=82\right)$ and in S1 $\left(E ; V_{\text {VGluT2 }}{ }^{+}, n=72 ; \mathrm{VGluT2}^{-}, n=64\right) ; \bar{X}$ is the median. $\boldsymbol{F}$, Cumulative histogram of the data in $\boldsymbol{D}$ and $\boldsymbol{E}$. $\boldsymbol{G}-\boldsymbol{I}$, Distributions of the area of the PSDs in M1 (G; VGluT2 ${ }^{+}, n=79 ;$ VGluT2 $\left.^{-}, n=83\right)$ and in S1 $\left(H_{;}\right.$VGluT2 ${ }^{+}, n=138$, VGluT2 $\left.{ }^{-}, n=67\right) ; \bar{X}$ is the median. Synapses on dendritic shafts were excluded for comparability. $\boldsymbol{I}$, Cumulative histogram of the data in $\boldsymbol{G}$ and $\boldsymbol{H}$. $\boldsymbol{J}$ - $\boldsymbol{L}$, Vesicle density estimates for $\mathrm{VGluT2}^{+}$and VGluT2 ${ }^{-}$boutons in M1 (J; VGluT2 ${ }^{+}, n=44$; $\left.\mathrm{VGluT2}^{-}, n=59\right)$ and in $\mathrm{S1}(\boldsymbol{K}$; VGluT2 $^{+}, n=68$; VGluT2 $\left.{ }^{-}, n=54\right) ; \bar{X}$ is the median. L, Cumulative histogram of the data in $\boldsymbol{J}$ and $\boldsymbol{K}$. Statistical analysis was performed using the nonparametric $\mathrm{M}-\mathrm{W}$ test, the results are shown in the box insets of the rightmost panels. ns: $p>0.05 ;{ }^{*} p \leq 0.05 ;{ }^{* *} p \leq 0.01$; ${ }^{* * *} p \leq 0.001 ;{ }^{* * *} p \leq 0.0001$.
}

$\leftarrow$ cuboid block that spans the entire cortical thickness and has a base area of $1 \mu \mathrm{m}^{2}$. For this, we measured the thickness of L4 in M1 and S1 in the same osmicated sections that were used for the unbiased disector counts and then multiplied the density of synapses formed by VGluT2 ${ }^{+}$boutons $\left(N_{\mathrm{V}}^{\mathrm{VGluT2}}\right)$ by the volume of L4 in this hypothetical cuboid. For M1, this number was $16.3 \pm 2.7$ synapses and, for $\mathrm{S} 1$, it was $31.7 \pm 4.9$ synapses (Fig. $3 A$ ). The thalamocortical projection to L4 of M1 thus provides approximately half as many synapses as the equivalent projection to S1 per unit volume of the L4 thalamocortical termination zone.

\section{Thalamocortical boutons rarely form synapses with smooth neurons in M1}

In both areas, the principal targets of synapses formed by VGluT2 ${ }^{+}$boutons were spines. In barrel cortex, 9.4\% of the synapses were formed with smooth dendritic shafts that had the ultrastructural features of GABAergic neurons (Fig. 3B). We followed these dendrites over multiple sections to confirm that they did not form spines; therefore, all of the synapses found were formed with the dendritic shaft (Fig. $2 B, E, F$ ). Smooth dendrites often contained large mitochondria (Fig. $2 B, E, F$ ) and occasionally formed beads (see Fig. 8). These features are characteristic for smooth, putatively GABAergic neurons (Somogyi et al., 1983; Kisvárday et al., 1985; Keller and White, 1987; Peters et al., 1991; Ahmed et al., 1997). In contrast, in M1 we found only one VGluT2 $^{+}$synapse out of the 174 synapses sampled that was formed with a smooth dendritic shaft. All other VGluT2 ${ }^{+}$boutons formed synapses with dendritic spines (Fig. 3B).

\section{D reconstructions of thalamocortical boutons in $\mathrm{M} 1$ and S1 L4}

The thalamocortical afferents to sensory areas are known to drive cortical activity in sensory areas, but how they achieve this effect is still being actively discussed. To explore further the detailed anatomical features of the thalamocortical synapses in M1 and S1, we reconstructed a large sample of VGluT2 ${ }^{+}$boutons in L4 of M1 $(n=61)$ and S1 $(n=72)$ and compared them with unlabeled boutons that formed asymmetric synapses $\left(\mathrm{VGluT}^{-}{ }^{-}\right.$) in M1 $(n=82)$ and $\mathrm{S} 1(n=64)$. Within these full reconstructions, we measured the volume of each bouton, the total mitochondria volume inside the bouton, the number of synapses it made, the volume of the spine heads it formed synapses with, and the area of the PSD. We also estimated the vesicle density inside boutons from single sections. Figure 4 shows a representative set of reconstructed boutons selected for morphological features that were characteristic of their area.

The first striking difference we found between the two areas (Fig. 5) was that VGluT2 ${ }^{+}$boutons in M1 only formed 1.3 synapses on average, whereas, in $\mathrm{S} 1, \mathrm{VGluT}_{2}{ }^{+}$boutons formed significantly more: 2.1 synapses per bouton on average $[p<0.0001$, Mann-Whitney (M-W) test]. VGluT2 ${ }^{-}$boutons in M1 made 1.1 synapses on average, similar to the 1.2 synapses made by VGluT2 ${ }^{-}$boutons in S1 (not significant, $p=0.10, \mathrm{M}-\mathrm{W}$ test). In comparison, only $33 \%$ of VGluT2 ${ }^{+}$boutons in S1 formed a single synapse (vs $81 \%$ of the VGluT2 ${ }^{-}$boutons in S1) and $\sim 30 \%$ of the VGluT2 ${ }^{+}$boutons formed 2 and 3 synapses each, with some even making 4 synapses. In M1, by contrast, $72 \%$ of the VGluT2 ${ }^{+}$ boutons formed only 1 synapse and $\mathrm{VGluT}^{+}$boutons rarely made $>2$ synapses (Fig. 5).

Individual VGluT2 ${ }^{+}$boutons that made more than one synapse (multisynaptic) tended to be larger than boutons making only one synapse (unisynaptic) (Figs. $6 A-C, 7 C-F$ ). VGluT2 ${ }^{+}$ 


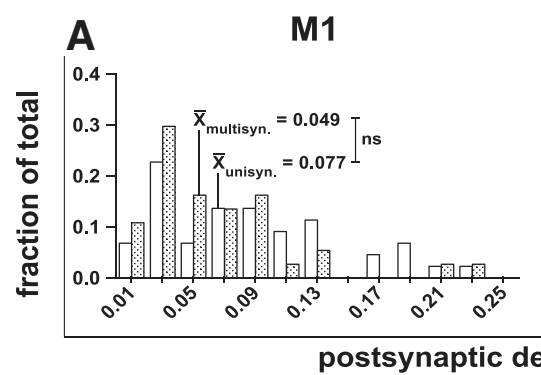

B

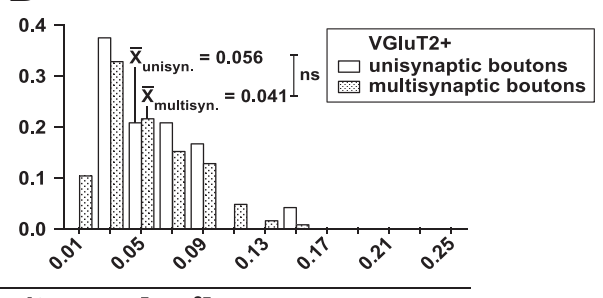

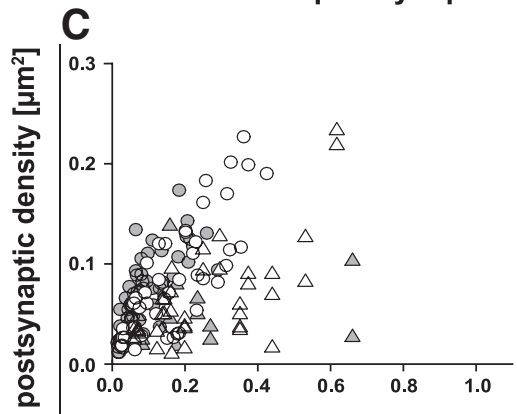

D
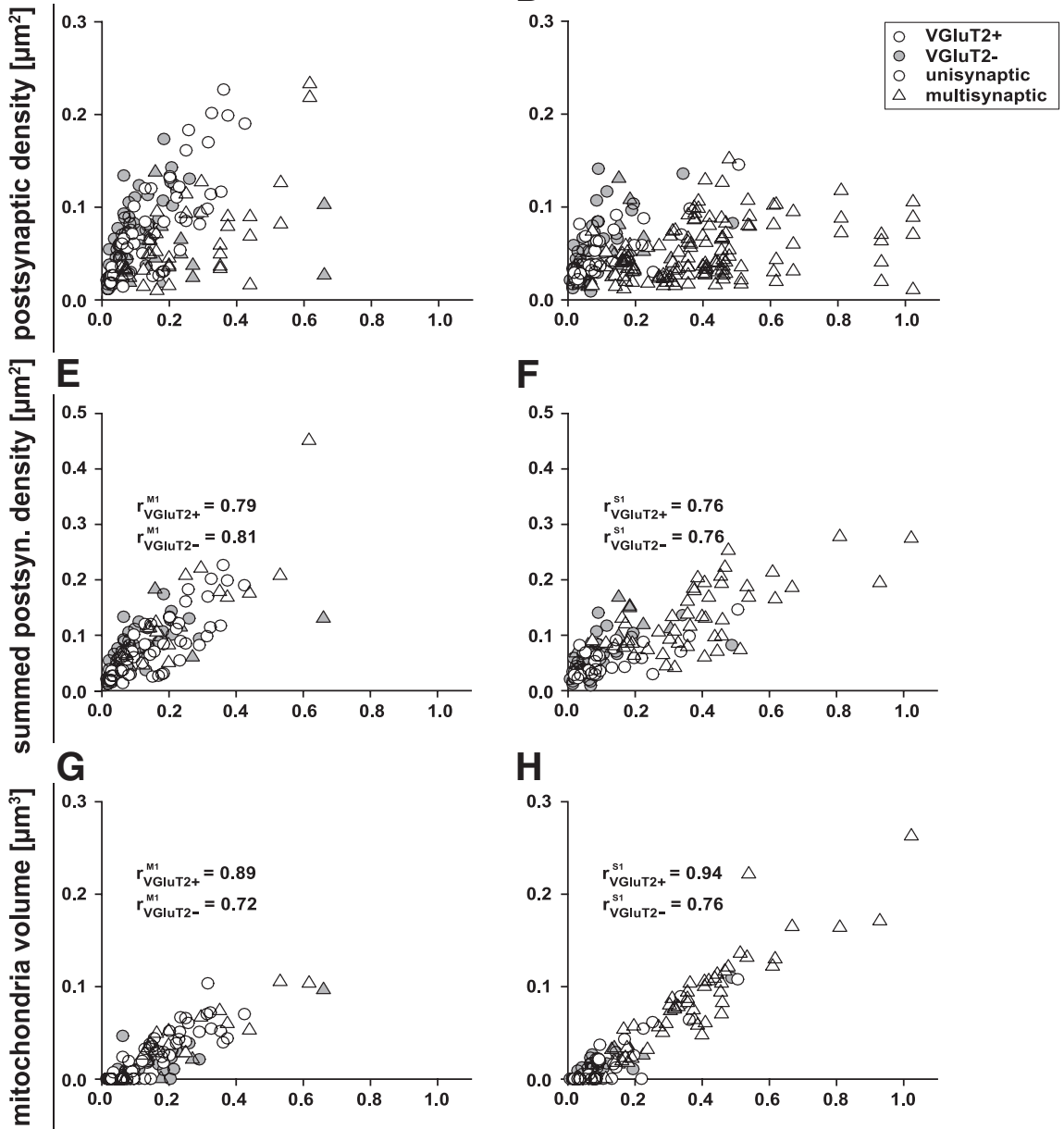

$\mathbf{F}$

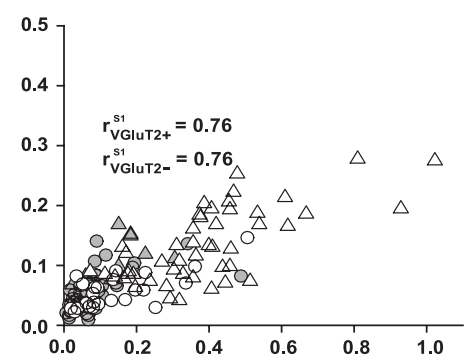

$\mathrm{H}$

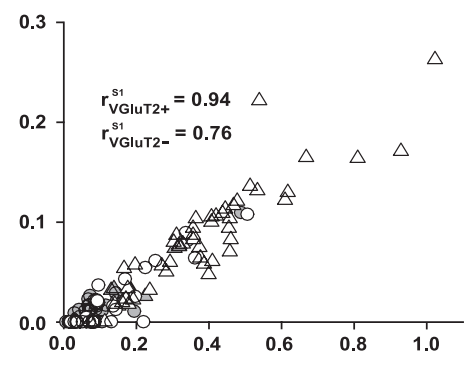

bouton volume $\left[\mu \mathrm{m}^{3}\right]$
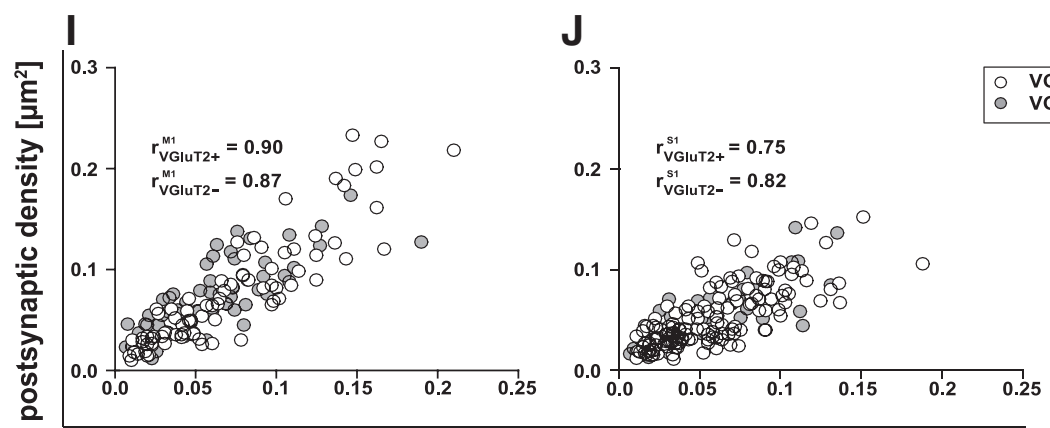

spine head volume $\left[\mu^{3}\right]$

Figure 7. Relationships of various morphological features of VGluT2 ${ }^{+}$and VGluT2 ${ }^{-}$boutons in M1 and S1 L4.A, B, Comparison of PSD sizes made by VGluT2 ${ }^{+}$boutons that either formed single synapses (unisynaptic) or multiple synapses (multisynaptic) in M1 ( $\boldsymbol{A}$; unisynaptic, $n=44$; multisynaptic, $n=37$ ) and in S1 ( $\boldsymbol{B}$; unisynaptic, $n=24$; multisynaptic, $n=125) ; \bar{X}$ is the median (M-W test). $\boldsymbol{C}, \boldsymbol{D}$, Scatter plots showing the relationship between the bouton volume and all individual PSDs made by a bouton in $\mathrm{M} 1$ ( $\boldsymbol{C}$; VGluT2 $^{+}, n=81$; $\left.\mathrm{VGluT2}^{-}, n=90\right)$ and in S1 (D; VGluT2 $\left.{ }^{+}, n=149 ; \mathrm{VGluT2}^{-}, n=79\right)$. In $\mathbf{C}-\boldsymbol{H}$, boutons are marked by different symbols indicating whether they were unisynaptic or multisynaptic (see box inset). $\boldsymbol{E}, \boldsymbol{F}$, Scatter plots showing the boutons were significantly larger than VGluT2 ${ }^{-}$boutons in both areas $(p<$ $0.0001, \mathrm{M}-\mathrm{W}$ test). At the same time, the median VGluT2 ${ }^{+}$bouton volume in $\mathrm{S} 1$ $\left(0.31 \mu \mathrm{m}^{3}\right)$ was larger than in M1 $(0.17$ $\left.\mu \mathrm{m}^{3}\right)(p<0.001, \mathrm{M}-\mathrm{W}$ test $)$ due to the longer tail in the bouton volume distribution in $\mathrm{S} 1$ (Fig. $6 A-C$ ). In contrast, the volumes of VGluT2 ${ }^{-}$boutons in both areas were not significantly different $(p=$ $0.55, \mathrm{M}-\mathrm{W}$ test). The volume occupied by mitochondria inside VGluT2 ${ }^{+}$boutons in S1 (median of $0.06 \mu \mathrm{m}^{3}$ ) was larger and had a longer tail in the distribution compared with M1 (median of $0.03 \mu \mathrm{m}^{3}$ ) (Fig. $6 D-F)$. The volume of the mitochondria inside a bouton always followed a strong linear correlation with the bouton volume itself (Fig. 7G,H).

PSDs made by VGluT2 ${ }^{+}$boutons in $\mathrm{S} 1$ (median $0.042 \mu \mathrm{m}^{2}$ ) were not significantly larger $(p=0.40, \mathrm{M}-\mathrm{W}$ test $)$ than those made by the VGluT2 ${ }^{-}$boutons (median $0.039 \mu^{2}$ ) (Fig. $6 H$ ). Intriguingly, we found that PSDs made by VGluT2 $^{+}$boutons in M1 (median 0.064 $\mu \mathrm{m}^{2}$ ) were significantly larger than their counterparts in S1 $(p<0.01, \mathrm{M}-\mathrm{W}$ test $)$, but not significantly larger $(p=0.10$, $\mathrm{M}-\mathrm{W}$ test) than the PSDs of M1 VGluT2 ${ }^{-}$ boutons (median $0.056 \mu \mathrm{m}^{2}$ ) (Fig. $6 G-I$ ). A similar picture emerged from the volumes of the targeted spine heads. The distribution had a longer tail in M1 compared with $\mathrm{S} 1$, but not significantly so ( $p=0.09, \mathrm{M}-\mathrm{W}$ test). It has been reported previously that the volume of the spine head is correlated to the area of its PSD (Harris and Stevens, 1989; Schikorski and Stevens, 1999; Arellano et al., 2007), a relationship that was evident in our data (Fig. 7I,J). Importantly, PSDs made by multisynaptic boutons in M1 and S1 were not larger than those made by unisynaptic boutons (Fig. $7 A-D)\left(p^{\mathrm{M} 1}=0.09, p^{\mathrm{S} 1}=\right.$ $0.25, \mathrm{M}-\mathrm{W}$ test). Only by summing up the areas of all PSDs that a bouton made was this "summed PSD" linearly correlated to the volume of the bouton (Fig. $7 E, F$ ).

$\leftarrow$

relationship between the bouton volume and the sum of all PSDs made by a bouton in $\mathrm{M} 1\left(E ; \mathrm{VGluT2}^{+}, n=61\right.$; VGluT2 ${ }^{-}$, $n=82)$, and in S1 (F; VGluT2 $\left.{ }^{+}, n=72 ; V_{\text {VluT2 }}{ }^{-}, n=64\right)$. $\boldsymbol{G}, \boldsymbol{H}$, Scatter plots showing the relationship between bouton volume and volume of mitochondria they contain in $\mathrm{M} 1(\mathbf{G}$; VGluT2 $^{+}, n=61 ;$ VGluT2 $\left.^{-}, n=82\right)$ and in $\mathrm{S1}\left(\mathrm{H}^{-} \mathrm{VGluT2}^{+}\right.$, $n=72$; VGluT2 $\left.{ }^{-}, n=64\right) . I, J$, Scatter plots of the relationship between spine head volume and the PSD area made on the spine head in $\mathrm{M} 1\left(\mathrm{I} ; \mathrm{VGluT2}^{+}, n=79 ; \mathrm{VGluT2}^{-}, n=83\right)$ and in $\mathrm{S} 1\left(\mathrm{~J} ; \mathrm{VGluT2}^{+}, n=138\right.$; VGluT2 $\left.{ }^{-}, n=67\right)$. Synapses formed with dendritic shafts were excluded for comparability. In $\boldsymbol{E}-\boldsymbol{J}, \boldsymbol{r}$ is the nonparametric Spearman correlation coefficient ( $p \leq 0.0001$ for all, $t$ test). 


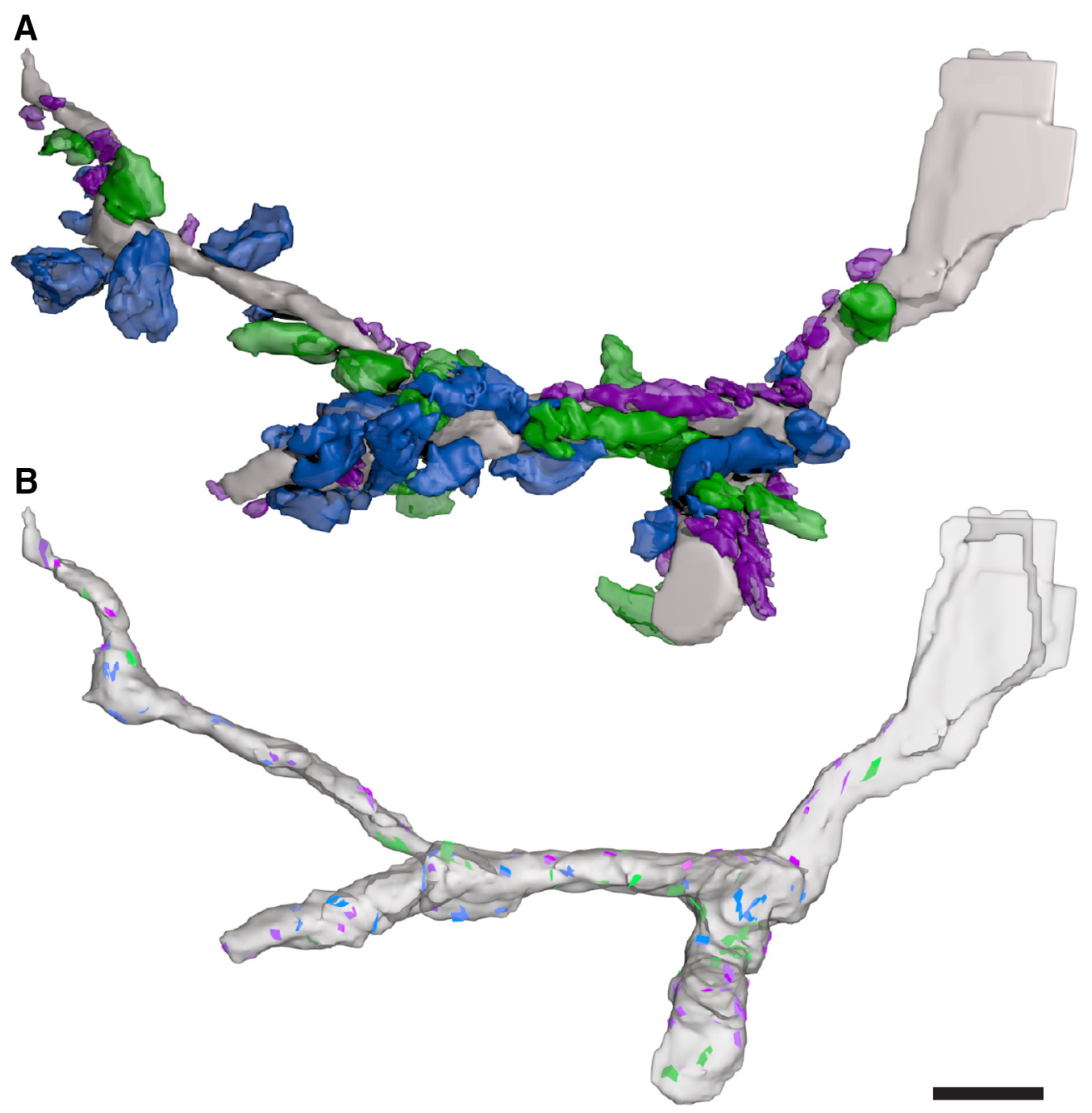

Figure 8. Proximal portion of a smooth, putatively GABAergic dendrite reconstructed from a tissue block in $\mathrm{L} 4$ of $S 1$. The dendrite emerged directly from its parent soma (thickening to the right). We reconstructed a total length of $31 \mu \mathrm{m}$, including two branch points and a local varicosity (to the left). $A$, Dendrite fragment formed a total of 90 synapses: 19 with VGluT2 ${ }^{+}$boutons (blue), 51 with VGluT2 ${ }^{-}$boutons (purple), and 20 symmetric synapses with putative GABAergic boutons (green). B, To visualize individual postsynaptic densities, the dendrite was made transparent. Asymmetric synapses made by VGluT2 ${ }^{+}$boutons are shown in blue, asymmetric synapses made by VGluT2 ${ }^{-}$boutons in purple, and symmetric synapses in green. Scale bar, $2 \mu \mathrm{m}$.

\section{Synaptic vesicle density estimation}

For a number of reconstructed boutons, we estimated the packing density of presynaptic vesicles by counting the number of profiles in single sections and dividing by the respective bouton volume contained in the section that was not occupied by mitochondria. The estimated vesicle densities had a similar median and characteristically large variation. In both areas, there was no significant difference between VGluT2 ${ }^{+}$and VGluT2 ${ }^{-}$boutons $\left(p^{\mathrm{M} 1}=0.73, p^{\mathrm{S} 1}=0.93, \mathrm{M}-\mathrm{W}\right.$ test $)$, similarly, the vesicle packing density of VGluT2 ${ }^{+}$boutons was not significantly different between M1 and S1 ( $p=0.33, \mathrm{M}-\mathrm{W}$ test) (Fig. $6 J-L)$.

\section{VGluT2 ${ }^{+}$boutons in barrel cortex form synapses with smooth neurons}

During the reconstructions of thalamic boutons in S1, we discovered two portions of smooth dendrites that were proximal to their soma and surrounded by VGluT2 ${ }^{+}$boutons forming synapses with the shaft. Thalamocortical synapses constituted $30 \%$ of all the asymmetric synapses formed with these two segments of the smooth dendrites. A full reconstruction of the longer dendrite segment, including all its presynaptic partners, is shown in Figure 8. This segment emerged directly from the soma and included two branch points and one local varicosity, which is a typical feature of smooth, putatively GABAergic dendrites. Over a total reconstructed length of $31 \mu \mathrm{m}$, this dendrite segment received a total of 90 synapses, of which 51 were asymmetric and made by VGluT2 ${ }^{-}$boutons, 19 were asymmetric and made by VGluT2 ${ }^{+}$ boutons, and 20 were symmetric synapses made by unlabeled boutons (putatively GABAergic). The high proportion of VGluT2 $^{+}$boutons exceeded what would be expected from the distribution of postsynaptic partners of VGluT2 ${ }^{+}$boutons that we found (Fig. 3B). Furthermore, we found two pairs of VGluT2 $^{+}$boutons that were made by the same axon and three pairs of boutons forming symmetric synapses that came from the same axon. Of the VGluT2 ${ }^{-}$boutons, we did not find any two boutons coming from the same axon. Interestingly, almost all VGluT2 $^{+}$boutons were clustered either around the 2 branch points or at a local varicosity $\sim 4 \mu \mathrm{m}$ away from the branch point. Conversely, the unlabeled boutons forming symmetric synapses and the VGluT2 ${ }^{-}$boutons were distributed more uniformly along the entire length of dendrite.

The VGluT2 ${ }^{-}$boutons were visibly smaller than the VGluT2 $^{+}$boutons and the boutons forming symmetric synapses (Fig. 8). Many of the VGluT2 ${ }^{+}$boutons that formed synapses 

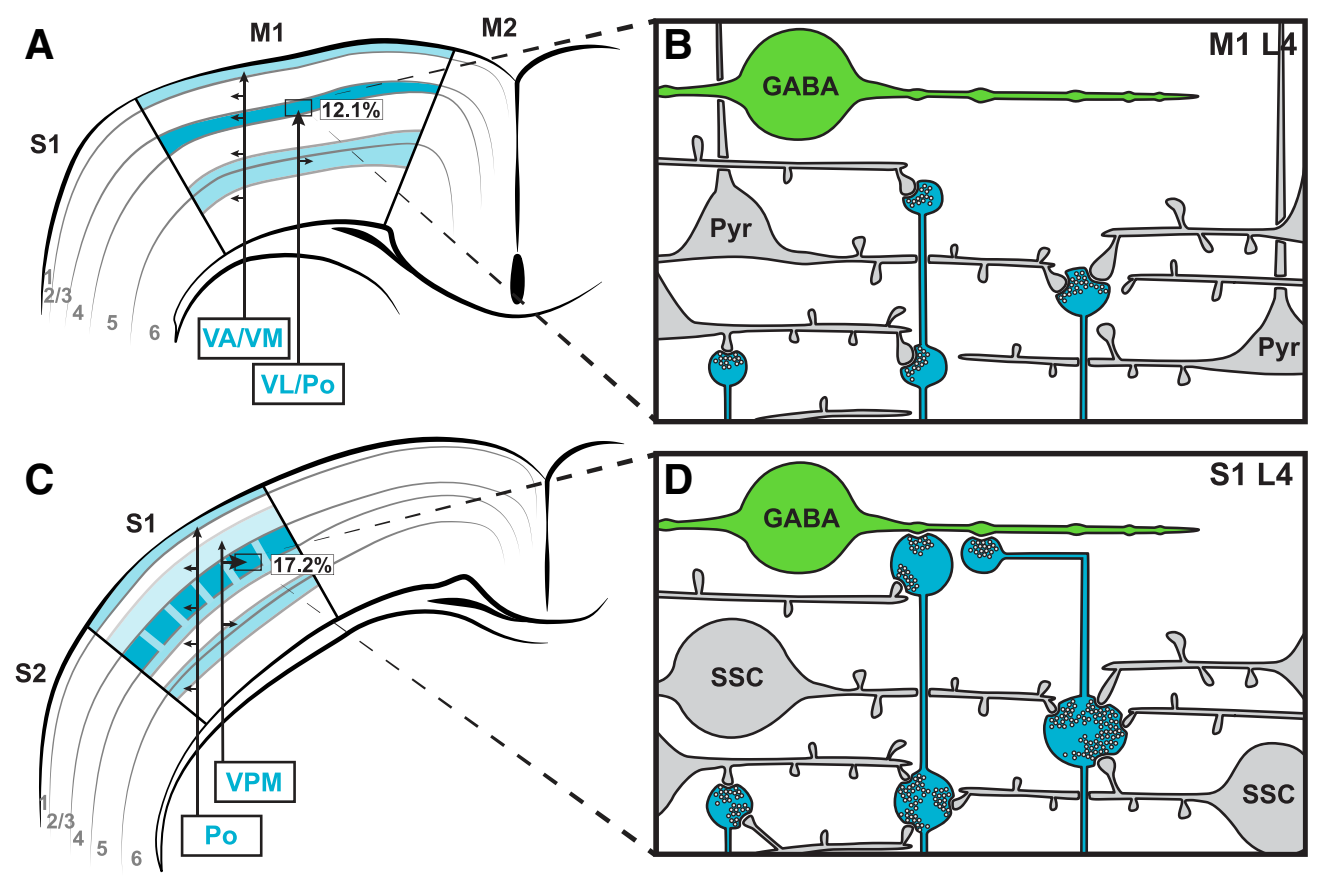

Figure 9. Schematic comparison of thalamic input to $L 4$ of $S 1$ and $M 1 . A$, In $L 4$ of $M 1, \sim 12.1 \%$ of synapses originate from the thalamus, most of them presumably from VL and $\mathrm{P} 0$; other termination zones include L1 (from VA and VM) and the L5/6 border (from VL and Po). B, Thalamic boutons (blue) in M1 L4 usually form one synapse, innervate pyramidal cells (Pyr) (Yamawaki et al., 2014) due to the absence of spiny stellate cells, make on average larger PSDs than in S1, and almost completely avoid dendrites of smooth (putative GABAergic) cells. C, In S1,VPM projects into the L 4 barrels, where it makes $\sim 17.2 \%$ of all asymmetric synapses, and to the $L 5 / 6$ border. Po projects to all laminae, in particular to $L 1$ and into the septa and upper $L 5$. D. Thalamic boutons in $S 1 L 4$ are larger compared with $M 1$ and usually form $>1$ synapse. They innervate spiny stellate cells (SSCs) and the dendrites of inhibitory cells, yet their PSDs are smaller compared with M1.

with the shaft were multisynaptic and formed other synapses with spines in the neuropil (not illustrated). A similar picture emerged from the second, smaller dendrite segment (not shown), which formed a total of 11 synapses over a length of $\sim 2.5 \mu \mathrm{m}$. VGluT2 ${ }^{+}$ boutons and VGluT2 ${ }^{-}$boutons made five synapses each and one bouton formed a symmetric synapse. This fragment was most likely relatively close to its cell soma because of its large-diameter shaft.

\section{Identifying thalamocortical boutons at EM in unlabeled sections of S1 L4}

Taken together, thalamic boutons in L4 of S1 and M1 share many features with boutons made by corticocortical axons. In barrel cortex L4, however, our analyses revealed that, unlike other boutons in the neuropil of L4, individual thalamocortical boutons typically formed synapses with two or more targets (Figs. 4, 5). In $\mathrm{S} 1$, this feature alone can be used to distinguish boutons of thalamic origin from others forming asymmetric synapses in the surrounding neuropil in the EM without requiring specific labeling of thalamocortical axons. Therefore, if sufficient length of an unlabeled axon in L4 of S1 is reconstructed, then the presence of multisynaptic boutons in the sample will indicate with a high degree of certainty that the axon originates from the thalamus.

\section{Discussion}

We found that, under a unit area of cortex, L4 in mouse M1 receives half as many thalamocortical synapses as S1 does. Synaptic boutons in $\mathrm{M} 1$ are smaller than those in S1 and usually form only one synapse. Nonetheless, the median synapse size is bigger in M1 than in S1. Atypically, the thalamic projection to M1 L4 forms virtually all of its synapses with spiny neurons, whereas $9 \%$ of synapses are formed with smooth neurons in S1.

\section{VGluT2 labeling reveals the termination laminae of thalamic afferents}

VGluT1 mRNA is predominantly expressed in the neocortex, cerebellar cortex, and hippocampus, whereas VGluT2 is expressed in the thalamus, brainstem, hypothalamus, and deep cerebellar nuclei (Fremeau et al., 2001; Herzog et al., 2001; Sakata-Haga et al., 2001; Kaneko et al., 2002; Varoqui et al., 2002). Because VGluT2 mRNA is expressed at high levels by cells in all thalamocortical relay nuclei of the dorsal thalamus in rodents (Hisano et al., 2000), VGluT2-immunohistochemistry has become the state-of-the-art method for labeling the thalamocortical systems of all sensory modalities in rodents (Kubota et al., 2007; Kuramoto et al., 2009; Coleman et al., 2010; Li et al., 2013).

The laminar pattern of VGluT2 labeling in both M1 and S1 corresponds to the known termination zones of thalamic afferents (Fig. 9). The ventral posteromedial nucleus (VPM) is a "core" projection into L4 barrels, lower L2/3, and to the L5/6 border of $\mathrm{S} 1$, whereas the posteromedial nucleus $(\mathrm{Po})$ projects in a "matrix-type" pattern sparsely to all laminae and densely to the barrel septa, upper L5, and L1 (Killackey, 1973; Donaldson et al., 1975; Wise and Jones, 1978; Koralek et al., 1988; Meyer et al., 2010; Viaene et al., 2011a). The projection from Po to L4 is very weak (Meyer et al., 2010) and boutons originating from Po are visibly smaller in the light microscope than boutons originating from VPM (Viaene et al., 2011a, 2011b).

In $\mathrm{M} 1$, the ventrolateral nucleus (VL) forms a core projection to L4 and the L5/6 border (and possibly also Po, see Yamawaki et al., 2014), while the ventroanterior (VA) and the ventromedial nuclei (VM) project in matrix-type patterns sparsely to all layers and densely to L1 (Strick and Sterling, 1974; Jones, 1975; Yamamoto et al., 1990; Kuramoto et al., 2009, 2015). VA and VM receive input from GABAergic afferents of the basal ganglia, 
whereas VL is driven by strong glutamatergic input from cerebellar nuclei (Jones, 2012).

\section{Thalamus contributes only a small fraction of the synapses in $\mathrm{L} 4$}

For the quantifications of thalamic synapses, it was instructive to compare our approach of using VGluT2 as a marker for thalamic boutons against previous methods. Using degeneration techniques to identify thalamocortical boutons, White (1978) found that $20 \%$ of synapses in L4 of S1 originate from the thalamus. Anterograde transport of lectin yielded $18-21 \%$ (Keller et al., 1985). With VGluT2 staining, we found that, in both S1 and M1, thalamocortical synapses form a small fraction of the asymmetric (excitatory) synapses in L4 (17.2\% and $12.1 \%$, respectively).

The barrel L4 in S1 contained the strongest VGluT2 fluorescence and was continuous with L4 of M1. In M1, L4 had strong VGluT2 staining, but was considerably thinner compared with S1. The quantitative EM revealed that the total number of synapses that the thalamus contributes to the cortical circuitry in L4 of M1 was only half that of S1. Commonly, the number of axon varicosities seen at the light microscope level are thought to equal the number of synapses (Meyer et al., 2010; Oberlaender et al., 2012). With this assumption, one would underestimate the number of thalamocortical synapses in S1 L4 by a factor of 2. For M1, it is an approximation ( 1.3 synapses per VGluT2 ${ }^{+}$bouton).

\section{Thalamocortical synapses in $\mathrm{S} 1$ are similar in size to corticocortical synapses but smaller than thalamocortical synapses in M1}

Although thalamocortical synapses form a minority of synapses in L4, they nonetheless are clearly effective in driving sensory cortices. The number of AMPA receptors in the postsynaptic membrane is proportional to the area of the PSD itself (Nusser et al., 1998; Tanaka et al., 2005). We found that PSDs of thalamocortical boutons in S1 are no larger than unlabeled asymmetric synapses in the surrounding neuropil and thus the amplitudes of thalamocortical and the corticocortical EPSPs are likely quite similar, as shown by in vivo experiments (Schoonover et al., 2014). Minimal stimulation of single thalamocortical fibers in slices of mouse S1 (Gil et al., 1999) and cat V1 (Stratford et al., 1996), however, evokes stronger responses in L4 neurons than do single corticocortical fibers. Thalamocortical synapses depress more strongly than corticocortical synapses (Stratford et al., 1996; Lee and Sherman, 2008), so it is to be expected that the high spontaneous activity of thalamic afferents causes relative depression (Banitt et al., 2007) that largely cancels out the amplitude difference between thalamocortical and corticocortical EPSPs in vivo (Castro-Alamancos et al., 1995; Chung et al., 2002; Boudreau and Ferster, 2005; Schoonover et al., 2014).

It has been suggested that the characteristically large thalamocortical "driver" boutons correlate with larger synapses and stronger EPSPs in S1 (Viaene et al., 2011b). Although VGluT2 ${ }^{+}$ boutons in $\mathrm{S} 1$ are large and usually multisynaptic, we found that the individual synapses were no bigger than those formed by VGluT2 ${ }^{-}$boutons. PSDs of VGluT2 ${ }^{+}$boutons in M1 were significantly larger than those in S1, indicating that they might elicit larger EPSPs. The disproportionately strong influence of thalamocortical input on cortical firing indicates that synchronous activation of thalamocortical synapses is critical (Hubel and Wiesel, 1962; Bruno and Sakmann, 2006; Banitt et al., 2007). Other circuit properties, such as amplification of thalamic input by the recurrent circuits within L4 (Douglas et al., 1989, 1995;
Stratford et al., 1996; Lübke et al., 2000), likely play a significant role in signal restoration.

\section{Lack of feedforward inhibition in the thalamocortical projection to M1}

VGluT2 $^{+}$boutons virtually never formed synapses with smooth dendrites in M1 L4. This is very different from S1 L4, where 9\% of $\mathrm{VGluT2}^{+}$synapses innervated smooth dendrites, which is similar to the thalamocortical projections to cat and monkey V1 (Ahmed et al., 1994; Latawiec et al., 2000; da Costa et al., 2009). The proximal location of VGluT2 ${ }^{+}$synapses on smooth neurons is reminiscent of the pattern in the cat, where some thalamocortical synapses are even formed directly on somata of GABAergic neurons (Freund et al., 1985a). This dense proximal input is likely a mechanism to ensure fast, reliable, and large-amplitude depolarization of interneurons after thalamic activation (Bagnall et al., 2011) and is probably why, in the sensory areas of all species studied, smooth (inhibitory) cells are more strongly and reliably driven by thalamic input than spiny (excitatory) neurons (Swadlow and Gusev, 2000; Porter et al., 2001; Swadlow, 2002; Gabernet et al., 2005; Cruikshank et al., 2007; Schiff and Reyes, 2012; Kloc and Maffei, 2014). Synchronous thalamocortical firing will thus drive monosynaptic activation of spiny cells in L4, followed by strong disynaptic feedforward inhibition (Ferster and Lindström, 1983; Douglas et al., 1989; Swadlow, 1989, 1990; Agmon and Connors, 1992; Gil and Amitai, 1996). Because one important role of feedforward inhibition in L4 of sensory areas is thought to be fast gain control (Douglas and Martin, 1991; Ohana et al., 2012), our observations raise the interesting question of why thalamic afferents in L4 of M1 do not follow this typical motif.

\section{M1 processing}

Various interpretations have emerged as to the flow of processing through M1. Weiler et al. (2008) proposed a "top-down" flow, with activity generated by inputs from S1 to L2/3 flowing down to L5 and then out of M1. Shipp et al. (2013) proposed an inference model in which a prediction error signal arrives via ascending inputs to L4 in sensory cortical areas and is corrected by a prediction signal arising from descending projections. Because M1 drives action, its prediction error is not revised, but instead is conveyed to the muscles, where the resulting action nulls the prediction error. They claim their theory demands an absence of L4 (Shipp et al., 2013). Both models thus assume the canonical thalamic input to L4 in M1 can be neglected.

An alternative model has been proposed by Kuramoto et al. (2009) whereby thalamic matrix-type (VA and VM) projections to L1 relay a gain increase or "ready" signal from the basal ganglia to the apical tuft of L5 pyramidal cells, whereas the thalamic core (VL) projection to L4 relays a motor command, or "go" signal from the cerebellum. This model fits our observations better and offers an explanation as to why the feedforward fast inhibitory gain control offered by direct thalamic input to smooth (GABAergic) cells appears to be missing in L4 of M1: the gain control is instead mediated via the matrix input to L1 inhibitory cells and pyramidal cell apical tufts.

Our study confirms that mouse M1 shares with S1 the canonical circuit motif of a core thalamic input to L4 and poses new questions about the role of the thalamic input to M1, which has been largely ignored in models of "agranular" cortical circuits.

\section{References}

Abercrombie M (1946) Estimation of nuclear population from microtome sections. Anat Rec 94:239-247. CrossRef Medline

Agmon A, Connors BW (1992) Correlation between intrinsic firing pat- 
terns and thalamocortical synaptic responses of neurons in mouse barrel cortex. J Neurosci 12:319-329. Medline

Ahmed B, Anderson JC, Douglas RJ, Martin KA, Nelson JC (1994) Polyneuronal innervation of spiny stellate neurons in cat visual cortex. J Comp Neurol 341:39-49. CrossRef Medline

Ahmed B, Anderson JC, Martin KA, Nelson JC (1997) Map of the synapses onto layer 4 basket cells of the primary visual cortex of the cat. J Comp Neurol 380:230-242. Medline

Arellano JI, Benavides-Piccione R, Defelipe J, Yuste R (2007) Ultrastructure of dendritic spines: correlation between synaptic and spine morphologies. Front Neurosci 1:131-143. CrossRef Medline

Bagnall MW, Hull C, Bushong EA, Ellisman MH, Scanziani M (2011) Multiple clusters of release sites formed by individual thalamic afferents onto cortical interneurons ensure reliable transmission. Neuron 71:180-194. CrossRef Medline

Banitt Y, Martin KA, Segev I (2007) A biologically realistic model of contrast invariant orientation tuning by thalamocortical synaptic depression. J Neurosci 27:10230-10239. CrossRef Medline

Barbas H, García-Cabezas MÁ (2015) Motor cortex layer 4: less is more. Trends Neurosci 38:259-261. CrossRef Medline

Boudreau CE, Ferster D (2005) Short-term depression in thalamocortical synapses of cat primary visual cortex. J Neurosci 25:7179-7190. CrossRef Medline

Brodmann K (1909) Vergleichende Lokalisationslehre der Großhirnrinde. Leipzig: JA Barth.

Bruno RM, Sakmann B (2006) Cortex is driven by weak but synchronously active thalamocortical synapses. Science 312:1622-1627. CrossRef Medline

Castro-Alamancos MA, Donoghue JP, Connors BW (1995) Different forms of synaptic plasticity in somatosensory and motor areas of the neocortex. J Neurosci 15:5324-5333. Medline

Chung S, Li X, Nelson SB (2002) Short-term depression at thalamocortical synapses contributes to rapid adaptation of cortical sensory responses in vivo. Neuron 34:437-446. CrossRef Medline

Clarke PG (1992) How inaccurate is the Abercrombie correction factor for cell counts? Trends Neurosci 15:211-212. CrossRef Medline

Coleman JE, Nahmani M, Gavornik JP, Haslinger R, Heynen AJ, Erisir A, Bear MF (2010) Rapid structural remodeling of thalamocortical synapses parallels experience-dependent functional plasticity in mouse primary visual cortex. J Neurosci 30:9670-9682. CrossRef Medline

Colonnier M (1968) Synaptic patterns on different cell types in the different laminae of the cat visual cortex: an electron microscope study. Brain Res 9:268-287. CrossRef Medline

Cruikshank SJ, Lewis TJ, Connors BW (2007) Synaptic basis for intense thalamocortical activation of feedforward inhibitory cells in neocortex. Nat Neurosci 10:462-468. Medline

da Costa NM, Martin KA (2009) The proportion of synapses formed by the axons of the lateral geniculate nucleus in layer 4 of area 17 of the cat. J Comp Neurol 516:264-276. CrossRef Medline

da Costa NM, Hepp K, Martin KA (2009) A systematic random sampling scheme optimized to detect the proportion of rare synapses in the neuropil. J Neurosci Methods 180:77-81. CrossRef Medline

Donaldson L, Hand PJ, Morrison AR (1975) Cortical-thalamic relationships in the rat. Exp Neurol 47:448-458. CrossRef Medline

Douglas RJ, Martin KA (1991) A functional microcircuit for cat visual cortex. J Physiol 440:735-769. CrossRef Medline

Douglas RJ, Martin KA, Whitteridge D (1989) A canonical microcircuit for neocortex. Neural Comput 1:480-488. CrossRef

Douglas RJ, Koch C, Mahowald M, Martin KA, Suarez HH (1995) Recurrent excitation in neocortical circuits. Science 269:981-985. CrossRef Medline

Ferster D, Lindström S (1983) An intracellular analysis of geniculo-cortical connectivity in area 17 of the cat. J Physiol 342:181-215. CrossRef Medline

Fremeau RT Jr, Troyer MD, Pahner I, Nygaard GO, Tran CH, Reimer RJ, Bellocchio EE, Fortin D, Storm-Mathisen J, Edwards RH (2001) The expression of vesicular glutamate transporters defines two classes of excitatory synapse. Neuron 31:247-260. CrossRef Medline

Freund TF, Martin KA, Somogyi P, Whitteridge D (1985a) Innervation of cat visual areas 17 and 18 by physiologically identified X- and Y- type thalamic afferents. II. Identification of postsynaptic targets by GABA immunocytochemistry and Golgi impregnation. J Comp Neurol 242:275291. CrossRef Medline
Freund TF, Martin KA, Whitteridge D (1985b) Innervation of cat visual areas 17 and 18 by physiologically identified X-and Y-type thalamic afferents. I. Arborization patterns and quantitative distribution of postsynaptic elements. J Comp Neurol 242:263-274. CrossRef Medline

Freund TF, Martin KA, Soltesz I, Somogyi P, Whitteridge D (1989) Arborisation pattern and postsynaptic targets of physiologically identified thalamocortical afferents in striate cortex of the macaque monkey. J Comp Neurol 289:315-336. CrossRef Medline

Gabernet L, Jadhav SP, Feldman DE, Carandini M, Scanziani M (2005) Somatosensory integration controlled by dynamic thalamocortical feedforward inhibition. Neuron 48:315-327. CrossRef Medline

García-Cabezas MÁ, Barbas H (2014) Area 4 has layer IV in adult primates. Eur J Neurosci 39:1824-1834. CrossRef Medline

Gil Z, Amitai Y (1996) Properties of convergent thalamocortical and intracortical synaptic potentials in single neurons of neocortex. J Neurosci 16:6567-6578. Medline

Gil Z, Connors BW, Amitai Y (1999) Efficacy of thalamocortical and intracortical synaptic connections: quanta, innervation, and reliability. Neuron 23:385-397. CrossRef Medline

Gray EG (1959) Axo-somatic and axo-dendritic synapses of the cerebral cortex. J Anat 93:420-433. Medline

Harris KM, Stevens JK (1989) Dendritic spines of CA 1 pyramidal cells in the rat hippocampus: serial electron microscopy with reference to their biophysical characteristics. J Neurosci 9:2982-2997. Medline

Herzog E, Bellenchi GC, Gras C, Bernard V, Ravassard P, Bedet C, Gasnier B, Giros B, El Mestikawy S (2001) The existence of a second vesicular glutamate transporter specifies subpopulations of glutamatergic neurons. J Neurosci 21:RC181. Medline

Hisano S, Hoshi K, Ikeda Y, Maruyama D, Kanemoto M, Ichijo H, Kojima I, Takeda J, Nogami H (2000) Regional expression of a gene encoding a neuron-specific $\mathrm{Na}+$-dependent inorganic phosphate cotransporter (DNPI) in the rat forebrain. Mol Brain Res 83:34-43. CrossRef Medline

Hubel DH, Wiesel TN (1962) Receptive fields, binocular interaction and functional architecture in the cat's visual cortex. J Physiol 160:106-154. CrossRef Medline

Jones EG (1975) Lamination and differential distribution of thalamic afferents within the sensory-motor cortex of the squirrel monkey. J Comp Neurol 160:167-203. CrossRef Medline

Jones EG (2012) The thalamus. New York: Springer Science and Business Media.

Kaneko T, Fujiyama F, Hioki H (2002) Immunohistochemical localization of candidates for vesicular glutamate transporters in the rat brain. J Comp Neurol 444:39-62. CrossRef Medline

Keller A, White EL (1987) Synaptic organization of GABAergic neurons in the mouse SmI cortex. J Comp Neurol 262:1-12. CrossRef Medline

Keller A, White EL, Cipolloni PB (1985) The identification of thalamocortical axon terminals in barrels of mouse Sml cortex using immunohistochemistry of anterogradely transported lectin (Phaseolus vulgarisleucoagglutinin). Brain Res 343:159-165. CrossRef Medline

Killackey HP (1973) Anatomical evidence for cortical subdivisions based on vertically discrete thalamic projections from the ventral posterior nucleus to cortical barrels in the rat. Brain Res 51:326-331. CrossRef Medline

Kisvárday ZF, Martin KA, Whitteridge D, Somogyi P (1985) Synaptic connections of intracellularly filled clutch cells: a type of small basket cell in the visual cortex of the cat. J Comp Neurol 241:111-137. CrossRef Medline

Kloc M, Maffei A (2014) Target-specific properties of thalamocortical synapses onto layer 4 of mouse primary visual cortex. J Neurosci 34:1545515465. CrossRef Medline

Koralek KA, Jensen KF, Killackey HP (1988) Evidence for two complementary patterns of thalamic input to the rat somatosensory cortex. Brain Res 463:346-351. CrossRef Medline

Krieg WJ (1946) Connections of the cerebral cortex. I. The albino rat. B. Structure of the cortical areas. J Comp Neurol 84:277-323. CrossRef Medline

Kubota Y, Hatada S, Kondo S, Karube F, Kawaguchi Y (2007) Neocortical inhibitory terminals innervate dendritic spines targeted by thalamocortical afferents. J Neurosci 27:1139-1150. CrossRef Medline

Kuramoto E, Furuta T, Nakamura KC, Unzai T, Hioki H, Kaneko T (2009) Two types of thalamocortical projections from the motor thalamic nuclei of the rat: a single neuron-tracing study using viral vectors. Cereb Cortex 19:2065-2077. CrossRef Medline

Kuramoto E, Ohno S, Furuta T, Unzai T, Tanaka YR, Hioki H, Kaneko T (2015) Ventral medial nucleus neurons send thalamocortical afferents 
more widely and more preferentially to layer 1 than neurons of the ventral anterior-ventral lateral nuclear complex in the rat. Cereb Cortex 25:221235. CrossRef Medline

Latawiec D, Martin KA, Meskenaite V (2000) Termination of the geniculocortical projection in the striate cortex of macaque monkey: a quantitative immunoelectron microscopic study. J Comp Neurol 419:306-319. CrossRef Medline

Lee CC, Sherman SM (2008) Synaptic properties of thalamic and intracortical inputs to layer 4 of the first- and higher-order cortical areas in the auditory and somatosensory systems. J Neurophysiol 100:317-326. CrossRef Medline

Li H, Fertuzinhos S, Mohns E, Hnasko TS, Verhage M, Edwards R, Sestan N, Crair MC (2013) Laminar and columnar development of barrel cortex relies on thalamocortical neurotransmission. Neuron 79:970-986. CrossRef Medline

Linderstrøm-Lang K, Holter H, Søeborg Ohlsen A (1935) Studies on enzymatic histochemistry. XIII. The distribution of enzymes in the stomach of pigs as a function of its histological structure. C R Trav Lab Carlsberg 20:66-127.

Lübke J, Egger V, Sakmann B, Feldmeyer D (2000) Columnar organization of dendrites and axons of single and synaptically coupled excitatory spiny neurons in layer 4 of the rat barrel cortex. J Neurosci 20:5300-5311. Medline

Meyer HS, Wimmer VC, Hemberger M, Bruno RM, de Kock CP, Frick A, Sakmann B, Helmstaedter M (2010) Cell type-specific thalamic innervation in a column of rat vibrissal cortex. Cereb Cortex 20:2287-2303. CrossRef Medline

Nahmani M, Erisir A (2005) VGluT2 immunochemistry identifies thalamocortical terminals in layer 4 of adult and developing visual cortex. J Comp Neurol 484:458-473. CrossRef Medline

Nakano K, Tokushige A, Kohno M, Hasegawa Y, Kayahara T, Sasaki K (1992) An autoradiographic study of cortical projections from motor thalamic nuclei in the macaque monkey. Neurosci Res 13:119-137. CrossRef Medline

Nusser Z, Lujan R, Laube G, Roberts JD, Molnar E, Somogyi P (1998) Cell type and pathway dependence of synaptic AMPA receptor number and variability in the hippocampus. Neuron 21:545-559. CrossRef Medline

Oberlaender M, de Kock CP, Bruno RM, Ramirez A, Meyer HS, Dercksen VJ, Helmstaedter M, Sakmann B (2012) Cell type-specific three-dimensional structure of thalamocortical circuits in a column of rat vibrissal cortex. Cereb Cortex 22:2375-2391. CrossRef Medline

Ohana O, Portner H, Martin KA (2012) Fast recruitment of recurrent inhibition in the cat visual cortex. PLoS One 7:e40601. CrossRef Medline

Paxinos G, Franklin KBJ (2004) The mouse brain in stereotaxic coordinates. Amsterdam: Elsevier.

Peters A, Palay SL (1996) The morphology of synapses. J Neurocytol 25: 687-700. CrossRef Medline

Peters A, Palay SL, Webster, H (1991) The fine structure of the nervous system: neurons and their supporting cells, Ed 3. New York: OUP.

Porter JT, Johnson CK, Agmon A (2001) Diverse types of interneurons generate thalamus-evoked feedforward inhibition in the mouse barrel cortex. J Neurosci 21:2699-2710. Medline

Sakata-Haga H, Kanemoto M, Maruyama D, Hoshi K, Mogi K, Narita M, Okado N, Ikeda Y, Nogami H, Fukui Y, Kojima I, Takeda J, Hisano S (2001) Differential localization and colocalization of two neuron-types of sodium-dependent inorganic phosphate cotransporters in rat forebrain. Brain Res 902:143-155. CrossRef Medline

Schiff ML, Reyes AD (2012) Characterization of thalamocortical responses of regular-spiking and fast-spiking neurons of the mouse auditory cortex in vitro and in silico. J Neurophysiol 107:1476-1488. CrossRef Medline

Schikorski T, Stevens CF (1997) Quantitative ultrastructural analysis of hippocampal excitatory synapses. J Neurosci 17:5858-5867. Medline

Schikorski T, Stevens CF (1999) Quantitative fine-structural analysis of olfactory cortical synapses. Proc Natl Acad Sci U S A 96:4107-4112. CrossRef Medline

Schoonover CE, Tapia JC, Schilling VC, Wimmer V, Blazeski R, Zhang W, Mason CA, Bruno RM (2014) Comparative strength and dendritic organization of thalamocortical and corticocortical synapses onto excitatory layer 4 neurons. J Neurosci 34:6746-6758. CrossRef Medline

Shepherd GM (2009) Intracortical cartography in an agranular area. Front Neurosci 3:337-343. CrossRef Medline
Shinoda Y, Kakei S (1989) Distribution of terminals of thalamocortical fibers originating from the ventrolateral nucleus of the cat thalamus. Neurosci Lett 96:163-167. CrossRef Medline

Shipp S (2005) The importance of being agranular: a comparative account of visual and motor cortex. Philos Trans R Soc Lond B Biol Sci 360:797814. CrossRef Medline

Shipp S, Adams RA, Friston KJ (2013) Reflections on agranular architecture: predictive coding in the motor cortex. Trends Neurosci 36:706-716. CrossRef Medline

Skoglund TS, Pascher R, Berthold CH (1997) The existence of a layer IV in the rat motor cortex. Cereb Cortex 7:178-180. CrossRef Medline

Somogyi P, Kisvárday ZF, Martin KA, Whitteridge D (1983) Synaptic connections of morphologically identified and physiologically characterized large basket cells in the striate cortex of cat. Neuroscience 10:261-294. CrossRef Medline

Stratford KJ, Tarczy-Hornoch K, Martin KA, Bannister NJ, Jack JJB (1996) Excitatory synaptic inputs to spiny stellate cells in cat visual cortex. Nature 382:258-261. CrossRef Medline

Strick PL, Sterling P (1974) Synaptic termination of afferents from the ventrolateral nucleus of the thalamus in the cat motor cortex: a light and electron microscope study. J Comp Neurol 153:77-106. CrossRef Medline

Swadlow HA (1989) Efferent neurons and suspected interneurons in S-1 vibrissa cortex of the awake rabbit: receptive fields and axonal properties. J Neurophysiol 62:288-308. Medline

Swadlow HA (1990) Efferent neurons and suspected interneurons in S-1 forelimb representation of the awake rabbit: receptive fields and axonal properties. J Neurophysiol 63:1477-1498. Medline

Swadlow HA (2002) Thalamocortical control of feed-forward inhibition in awake somatosensory "barrel” cortex. Philos Trans R Soc Lond B Biol Sci 357:1717-1727. CrossRef Medline

Swadlow HA, Gusev AG (2000) The influence of single VB thalamocortical impulses on barrel columns of rabbit somatosensory cortex. J Neurophysiol 83:2802-2813. Medline

Tanaka J, Matsuzaki M, Tarusawa E, Momiyama A, Molnar E, Kasai H, Shigemoto R (2005) Number and density of AMPA receptors in single synapses in immature cerebellum. J Neurosci 25:799-807. CrossRef Medline

Tennant KA, Adkins DL, Donlan NA, Asay AL, Thomas N, Kleim JA, Jones TA (2011) The organization of the forelimb representation of the C57BL/6 mouse motor cortex as defined by intracortical microstimulation and cytoarchitecture. Cereb Cortex 21:865-876. CrossRef Medline

Varoqui H, Schäfer MK, Zhu H, Weihe E, Erickson JD (2002) Identification of the differentiation-associated $\mathrm{Na}+/ \mathrm{PI}$ transporter as a novel vesicular glutamate transporter expressed in a distinct set of glutamatergic synapses. J Neurosci 22:142-155. Medline

Viaene AN, Petrof I, Sherman SM (2011a) Properties of the thalamic projection from the posterior medial nucleus to primary and secondary somatosensory cortices in the mouse. Proc Natl Acad Sci U S A 108: 18156-18161. CrossRef Medline

Viaene AN, Petrof I, Sherman SM (2011b) Synaptic properties of thalamic input to layers $2 / 3$ and 4 of primary somatosensory and auditory cortices. J Neurophysiol 105:279-292. CrossRef Medline

Weiler N, Wood L, Yu J, Solla SA, Shepherd GM (2008) Top-down laminar organization of the excitatory network in motor cortex. Nat Neurosci 11:360-366. CrossRef Medline

White EL (1978) Identified neurons in mouse SmI cortex which are postsynaptic to thalamocortical axon terminals: a combined Golgi-electron microscopic and degeneration study. J Comp Neurol 181:627-661. CrossRef Medline

Winfield DA, Powell TP (1983) Laminar cell counts and geniculo-cortical boutons in area 17 of cat and monkey. Brain Res 277:223-229. CrossRef Medline

Wise SP, Jones EG (1978) Developmental studies of thalamocortical and commissural connections in the rat somatic sensory cortex. J Comp Neurol 178:187-208. CrossRef Medline

Yamamoto T, Kishimoto Y, Yoshikawa H, Oka H (1990) Cortical laminar distribution of rat thalamic ventrolateral fibers demonstrated by the PHA-L anterograde labeling method. Neurosci Res 9:148-154. CrossRef Medline

Yamawaki N, Borges K, Suter BA, Harris KD, Shepherd GM (2014) A genuine layer 4 in motor cortex with prototypical synaptic circuit connectivity. eLife 3:e05422. CrossRef Medline 